\title{
Thermal Atomic Layer Deposition of Polycrystalline Gallium Nitride
}

\author{
Sourish Banerjee, ${ }^{\circledR}$ Antonius A. I. Aarnink, Dirk J. Gravesteijn, and Alexey Y. Kovalgin* \\ MESA+ Institute for Nanotechnology, University of Twente, P. O. Box 217, 7500AE Enschede, The Netherlands
}

Supporting Information

\begin{abstract}
We report the successful preparation of polycrystalline gallium nitride (poly-GaN) layers by thermal atomic layer deposition (ALD) at low temperatures $\left(375-425^{\circ} \mathrm{C}\right.$ ) from trimethylgallium (TMG) and ammonia $\left(\mathrm{NH}_{3}\right)$ precursors. The growth per cycle (GPC) is found to be strongly dependent on the $\mathrm{NH}_{3}$ pulse duration and the $\mathrm{NH}_{3}$ partial pressure. The pressure dependence makes the ALD atypical. We propose that the ALD involves (i) the reversible formation of the hitherto-

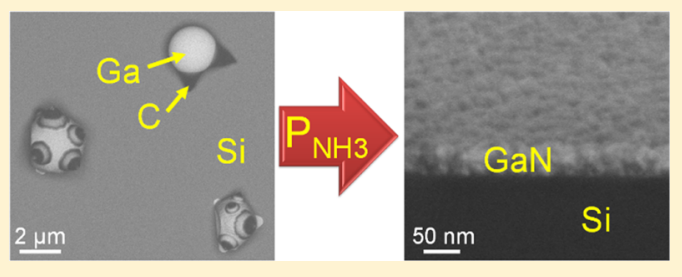
unreported TMG: $\mathrm{NH}_{3}$ surface adduct, resulting from $\mathrm{NH}_{3}$ physisorbing on a TMG surface site and (ii) the irreversible conversion of neighboring surface adducts to $\mathrm{Ga}-\mathrm{NH}_{2}-\mathrm{Ga} \mathrm{linkages}$. The pressure dependence arises from the presumed reversible nature of the adduct formation on the surface, equivalent to the known reversible nature of its formation in the gas phase in metal organic chemical vapor deposition reactions. Using in situ spectroscopic ellipsometry (SE), the GPC monitored as a function of several ALD parameters is as high as $0.1 \mathrm{~nm} / \mathrm{cycle}$ at $60 \mathrm{~s}$ $\mathrm{NH}_{3}$ pulse and 1.3 mbar $\mathrm{NH}_{3}$ partial pressure. The changes in the growth pattern (as monitored by $\mathrm{SE}$ ) caused by changes in the ALD parameters support the proposed growth model. Ex situ characterization reveals that the layer is carbon-free, has a polycystalline wurtzitic structure, and shows a decent conformaility over Si trenches. Tuning the ALD recipe allows us to vary the layer composition from Ga-rich to stoichiometric GaN. The Ga richness is attributed to the simultaneous TMG dissociation at the deposition temperatures. This work is the first full-scale report on low temperature thermal ALD of poly-GaN from industrial precursors, occurring via a novel chemical pathway and not requiring any radical assistance (such as plasma) as used before.
\end{abstract}

\section{INTRODUCTION}

Gallium nitride ( $\mathrm{GaN})$, a group III-V semiconductor, has several material benefits over silicon $(\mathrm{Si})$, the latter of which commonly used for consumer-grade electronic applications. $\mathrm{GaN}$ has a direct and wide band gap (3.39 eV), high breakdown field $\left(5 \mathrm{MV} \mathrm{cm}{ }^{-1}\right)$, electron mobility $\left(1500 \mathrm{~cm}^{2}\right.$ $\mathrm{V}^{-1} \mathrm{~s}^{-1}$ ), and thermal stability (melting point of $2500{ }^{\circ} \mathrm{C}$ ), combined with the ability to form a high-mobility twodimensional electron gas (2 DEG) when deposited on another III-V semiconductor. ${ }^{1-6}$ These attractive properties, beneficial for utilizing $\mathrm{GaN}$ in high-power and high-frequency electronic and light emitting devices, ${ }^{7,8}$ however, mainly exist for monocrystalline GaN. Epitaxial growth of high-quality GaN monocrystals requires an excellent lattice match with the underlying substrate. A GaN substrate naturally offers the best solution; however, it is prohibitively expensive at large sizes, making it not suited for device mass production. Other substrates offering a good scope for epitaxy are sapphire, silicon carbide, and $\mathrm{Si}(111)$, $^{7,8}$

Combined with the mature Si technology and by using $\mathrm{Si}$ substrate as a low-cost alternative, GaN has the potential to expand the range of devices and applications. ${ }^{9} \mathrm{Si}$ additionally offers benefits over other substrates such as sapphire, for instance, good thermal and electrical conductivity, thus allowing fabrication of devices directly on it. ${ }^{8,10}$ However, this comes with tradeoffs. GaN-on-Si devices can face critical issues associated with the lattice mismatch and thermal expansion coefficient (TCE) difference between GaN and Si.
Whereas the lattice mismatch creates dislocations in $\mathrm{GaN}$ (thereby reducing the internal quantum efficiency of light emitting devices), the TCE difference causes film cracking and wafer bowing. ${ }^{11}$ In addition, the direct epitaxy of $\mathrm{GaN}$ on $\mathrm{Si}$ is associated with meltback etching of $\mathrm{Si}$, which deteriorates the GaN crystal quality. ${ }^{12,13}$ A solution to these issues is the predeposition of buffer layers comprising (but not limited to) aluminum nitride (AlN), AlN/GaN superlattice, graded AlGaN, and their combination. ${ }^{12,14-16}$ However, the buffer layers, typically a few micron thick, can cause wafer bowing and breakage. All of these keep the epitaxial GaN-on-Si technology still in a developing phase.

The polycrystalline version of $\mathrm{GaN}$ (named poly-GaN) has been largely overshadowed by its monocrystalline counterpart. Thin submicron poly-GaN films enable a growing number of specific device concepts and applications, such as sensors, ${ }^{17-20}$ LEDs, ${ }^{21-24}$ and thin-film transistors. ${ }^{25,26}$ Briefly, the motivation for studying thin poly-GaN films (instead of epi-GaN) can be compared to utilizing poly- or amorphous Si films as lowerefficiency but cost-effective alternatives to monocrystalline $\mathrm{Si}$ for making large-area displays and solar cells. ${ }^{27}$ Although one or more of the aforementioned properties of epitaxially grown $\mathrm{GaN}$ may be deteriorated in the polycrystalline version, the research interest lies in identifying to what extent poly-GaN

Received: June 21, 2019

Revised: August 19, 2019 
can be exploited, especially since its deposition conditions are more relaxed compared to epi-GaN. For instance, the applicability of diverse substrates (e.g., glass ${ }^{28}$ and flexible polymers ${ }^{26}$ ) due to the low deposition temperatures can broaden the application range. ${ }^{26,28,29}$ The relaxation of the necessity of buffer-layers also enables poly-GaN to be directly grown on the corresponding substrates. ${ }^{30}$ Poly-GaN layers can be prepared by a variety of techniques; ${ }^{19,29}$ among them, atomic layer deposition (ALD) is highly relevant since the technique has become a major player in the electronics industry, owing to its monolayer-level thickness control combined with excellent spatial uniformity and conformality. $^{31-35}$

For poly-GaN ALD (further referred to as GaN ALD), organometallic (e.g., trimethylgallium (TMG) or triethylgallium (TEG)) or halide-based inorganic Ga precursors (e.g., $\mathrm{GaCl}_{3}$ ) have been used, often utilizing $\mathrm{NH}_{3}$ or $\mathrm{N}_{2}-\mathrm{H}_{2}$ as a nitrogen source. ${ }^{30,36-52}$ The challenge of ALD by purely thermal means (i.e., without using additional activation techniques) is the activation of the nitrogen precursor, which is chemically very stable. Thermal ALD of $\mathrm{GaN}$ from $\mathrm{GaCl}_{3}$ and $\mathrm{NH}_{3}$ has been reported to occur at temperatures exceeding $400{ }^{\circ} \mathrm{C} .{ }^{49-51}$ The halide precursor however exhibits several drawbacks, such as difficulty in delivery due to its low vapor pressure (demanding supply- and gas-line heating), etching of the reactor walls from corrosive by-products (e.g., $\mathrm{HCl}$ ), and $\mathrm{Cl}$ incorporation in the growing film. ${ }^{39}$ On the contrary, ALD with TMG or TEG typically demands resorting to low temperatures $\left(<400{ }^{\circ} \mathrm{C}\right)$ since these $\mathrm{Ga}$ precursors tend to dissociate at higher temperatures, resulting in significant Gaand C-contamination in the layers. ${ }^{53}$ In order to carry out the ALD at sub-dissociation temperatures of the organometallics, researchers resort to additional means of activation, such as with plasma, ${ }^{30,37,39,43,45}$ hot filament, ${ }^{48}$ or electron beam, ${ }^{47}$ to dissociate the $\mathrm{N}$ precursor into radicals $\left(\mathrm{NH}_{x}, x=0-2\right.$ and $\left.\mathrm{H}\right)$. Such radical-enhanced ALD lowers the process temperature and enables an ALD window for GaN.

However, achieving purely thermal GaN ALD from TMG and $\mathrm{NH}_{3}$ at low temperatures and without radical assistance has major advantages. First, the presence of ions and radiation in plasma may cause damage to the substrate or the growing film. ${ }^{54}$ Second, involving radicals may limit film conformality, especially in high-aspect-ratio structures, due to their recombination tendency. ${ }^{54,55}$ The same issue limits the application of radical-assisted ALD to only single-wafer reactors; scaling up to batch reactors is not straightforward. A purely thermal ALD process allows us to resolve the above issues.

In this work, we propose a low-temperature chemical route (perhaps previously overlooked by the GaN ALD community) that can be used to deposit poly-GaN films from TMG and $\mathrm{NH}_{3}$, without cracking $\mathrm{NH}_{3}$ into radicals. The GaN growth can occur at $400{ }^{\circ} \mathrm{C}$ with a growth rate per cycle (GPC) as high as $0.1 \mathrm{~nm} /$ cycle. This novel ALD route was identified from (i) the previously reported ALD mechanism of AlN films using $\mathrm{NH}_{3}$ and (the chemically similar to TMG) trimethylaluminum (TMA) and (ii) supported by the reported chemical models of $\mathrm{GaN}$ growth in metal organic chemical vapor depositon (MOCVD).

Similar to the TMA: $\mathrm{NH}_{3}$ surface adduct species that participates in AlN $\mathrm{ALD}^{56}$ and equivalent to the TMG: $\mathrm{NH}_{3}$ gas-phase adduct species known for GaN MOCVD reactions, ${ }^{57}$ we hypothesize the existence of the TMG: $\mathrm{NH}_{3}$ surface adduct as the necessary species to enable GaN ALD in a purely thermal mode. Few earlier publications ${ }^{58,59}$ on thermal GaN ALD from TMG and $\mathrm{NH}_{3}$ reported high-temperature (>500 ${ }^{\circ} \mathrm{C}$ ) processes, primarily focusing on the material and electrical characterization for potential optical/electronic devices, without detailed investigation into the film composition or growth mechanism as pursued in this work. Our recent preceding publication on GaN ALD using the same precursors revealed significant gallium and carbon incorporation into the layers from the dissociation of TMG at similar elevated temperatures; we presented a clear relationship between the carbon content and the deposition temperature and pressure. ${ }^{53}$ Besides, in the two earlier publications, no demonstration of the existence of an ALD window was provided, as presented here for the first time.

\section{EXPERIMENTAL SECTION}

The growth experiments were performed in a home-built single-wafer hot-wall ALD reactor $\left(32 \mathrm{~cm}^{3}\right.$ in volume $)$ attached to a load-lock and evacuated by a turbo-molecular pump (Pfeiffer Vacuum). The latter ensured a base pressure of $10^{-7}$ mbar. A computer-controlled throttle valve was used to establish the desired reactor pressure during the ALD, which was varied from $10^{-3}$ to $10^{1} \mathrm{mbar}$. The reactor was a cross-flow type, and the precursors (TMG: $99.9999 \%$ electronic grade; $\left.\mathrm{NH}_{3}: 99.999 \%\right)$ were introduced using an inert carrier gas (Ar: 99.999\%), with high-speed ALD valves (Swagelok) of $0.1 \mathrm{~s}$ time resolution. The Ar flow rate was $25 \mathrm{sccm}$ for TMG and $\mathrm{NH}_{3}$, and the $\mathrm{NH}_{3}$ flow rate was $5 \mathrm{sccm}$. The $\mathrm{NH}_{3}$ flow rate was intentionally kept low to minimize problems during purging especially at high reactor pressures since the gas is known to have a high sticking coefficient. The partial pressure of $\mathrm{NH}_{3}$ was adjusted only by adjusting the reactor pressure while maintaining the precursor and carrier flow rates constant. $4^{\prime \prime}$ p-type $\operatorname{Si}(111)$ wafers were used as the substrate. Before introducing into the load-lock, they were cleaned in an ultraclean processing line, which included ozone-steam treatment to remove the metallic and organic contaminants followed by a $1 \%$ HF dip to strip the native oxide, with final rinsing in deionized (DI) water.

A Woollam M-2000 spectroscopic ellipsometer (SE) operating in the wavelength range of 245-1688 nm was used for in situ monitoring the GaN growth. The ellipsometric analyses were performed with J. A. Woollam CompleteEASE software. Because $\mathrm{GaN}$ is a wide band gap semiconductor $(\mathrm{Eg}$ $=3.39 \mathrm{eV}$ equivalent to $365.8 \mathrm{~nm}$ ), the Cauchy optical model ${ }^{60}$ was used for wavelengths beyond $500 \mathrm{~nm}$. This model proved to be effective as the thicknesses obtained by SE were in close agreement with that by a scanning electron microscope (SEM). In situ SE enabled monitoring in real time the changes in the GPC with deposition parameters such as temperature and pressure.

Several ex situ analysis techniques were employed to characterize the layers. The thickness and morphology were studied by a Zeiss Merlin scanning electron microsope (SEM) equipped with an energy selective backscatter (ESB) detector and with a Philips CM300ST-FEG high resolution transmission electron microscope (HRTEM). The polycrystalline structure was revealed from grazing incidence X-ray diffraction (GIXRD) using a Malvern Panalytical X’Pert powder X-ray diffractometer, in addition to HRTEM. The composition and the nature of chemical bonds were obtained from sputterdepth-profiled X-ray photoelectron spectroscopy (XPS) 
TMG pulse \& purge

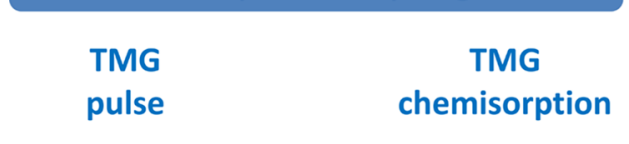

$\mathrm{NH}_{3}$ pulse \& purge
GaN monolayer formation

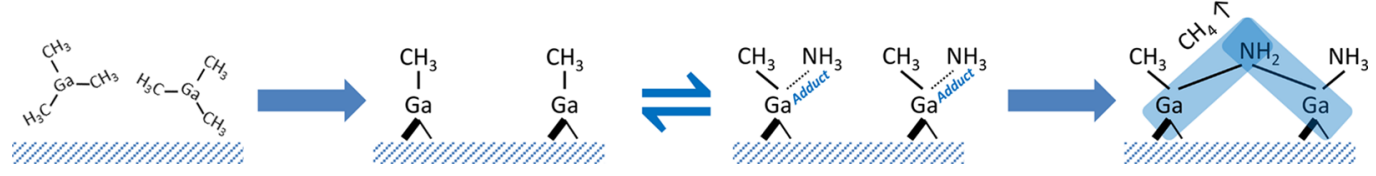

Figure 1. Proposed mechanism of thermal GaN ALD through (i) TMG chemisorption, (ii) reversible formation of the TMG:NH $\mathrm{TH}_{3}$ surface adduct, and (iii) irreversible conversion of neighboring surface adducts into a $\mathrm{Ga}-\mathrm{NH}_{2}-\mathrm{Ga}$ linkage (shaded in blue), signifying the formation of a GaN unit. Formation of a $\mathrm{GaN}$ monolayer implies completing the surface coverage with the $\mathrm{Ga}-\mathrm{NH}_{2}-\mathrm{Ga}$ linkages. A preliminary version of the model was presented earlier. ${ }^{52}$ To note, the TMG chemisorption schematic only serves to show that a $-\mathrm{CH}_{3}$-terminated surface can be expected after the TMG pulse, after several ALD cycles. The exact nature of TMG chemisorption is beyond the scope of this study.

analysis with a PHI Quantera SXM and from Fourier transform infrared (FTIR) spectroscopy from Thermo Scientific. All simulations were performed using PTC Mathcad software.

\section{SURFACE REACTIONS LEADING TO GAN ALD}

3.1. Reported Mechanism of Thermal AIN ALD. The mechanism of thermal ALD of AlN from TMA and $\mathrm{NH}_{3}$ precursors has been widely reported ${ }^{56,61-66}$ unlike that of GaN. On a silica substrate, TMA chemisorbs on hydroxyl and/ or siloxane sites by the loss of two methyl $\left(-\mathrm{CH}_{3}\right)$ groups, forming monomethyl aluminum $\left(\mathrm{Al}-\mathrm{CH}_{3}\right) \cdot{ }^{67}$ The subsequently dosed $\mathrm{NH}_{3}$ physisorbs on the $\mathrm{Al}-\mathrm{CH}_{3}$ unit, resulting in the socalled TMA: $\mathrm{NH}_{3}$ surface adduct. Such an adduct unit therefore contains an $\mathrm{Al}$ atom chemisorbed to the substrate, a $-\mathrm{CH}_{3}$ group bonded with the $\mathrm{Al}$ and a $\mathrm{NH}_{3}$ molecule physisorbed to the $\mathrm{Al}^{56,61}$ The chemical origin of the surface adduct is attributed to TMA and $\mathrm{NH}_{3}$, being strong Lewis acid and Lewis base, respectively. ${ }^{68}$ Therefore, the adduct forms already at low temperatures on the surface ${ }^{56,61}$ or in the gas phase $^{68,69}$ through a strong electrostatic force of attraction between $\mathrm{Al}$ and $\mathrm{N}$.

The surface adduct, however, is not stable at high temperatures. Typically beyond $300{ }^{\circ} \mathrm{C}$, the physisorbed $\mathrm{NH}_{3}$ hydrogenates the $-\mathrm{CH}_{3}$ group of a neighboring adduct unit, eliminating a $\mathrm{CH}_{4}$ molecule and concurrently forming an $\mathrm{Al}-\mathrm{NH}_{2}-\mathrm{Al}$ linkage between the two units; ${ }^{56}$ this reaction is self-limiting in nature. The formation of $\mathrm{Al}-\mathrm{NH}_{2}-\mathrm{Al}$ linkages over the entire surface implies a monolayer growth of AlN. The subsequently pulsed TMA chemisorbs on the $-\mathrm{NH}_{2}$ - unit of the linkage, reterminating the surface with $-\mathrm{CH}_{3}$ groups and forming half of the next monolayer. ${ }^{56}$ Such a regenerative feature of the surface reactions between TMA and $\mathrm{NH}_{3}$ is proposed to be a viable chemical pathway in the ALD of AlN. $^{56,62}$

3.2. Proposed Mechanism of Thermal GaN ALD. Unlike the TMA: $\mathrm{NH}_{3}$ surface adduct, the experimental evidence of the TMG: $\mathrm{NH}_{3}$ surface adduct and its role in GaN ALD has not been reported to the best of our knowledge. This could be partly because the nature of the interaction of TMG with the substrate $\left(\mathrm{Si}, \mathrm{SiO}_{2}\right)$ is somewhat different from that of TMA. Whereas TMA can chemisorb onto these surfaces and remains stable at the ALD temperature of AlN $\left(300-400{ }^{\circ} \mathrm{C}\right),{ }^{64} \mathrm{TMG}$ starts to dissociate on the surface roughly from $150{ }^{\circ} \mathrm{C}$, successively eliminating the $-\mathrm{CH}_{3}$ groups. $^{70,71}$ At the deposition temperatures used in this study ( $350{ }^{\circ} \mathrm{C}$ and beyond), it is questionable whether TMG still possesses one or more $-\mathrm{CH}_{3}$ groups. However, based on the experimental results (Sections 6 and 7 and Figure S1), we propose that, after several 250-300 ALD cycles, the substrate can accommodate the necessary coverage of $-\mathrm{CH}_{3}$ terminated sites to support the further growth of $\mathrm{GaN}$. A brief discussion on Figure S1 is presented in Section 6.2.4.

Equivalent to the AlN ALD, we propose a growth model for the GaN ALD (Figure 1). After the TMG pulse, the dosage of $\mathrm{NH}_{3}$ to the $-\mathrm{CH}_{3}$-terminated surface leads to the TMG:NH surface adduct. Aided thermally, neighboring adduct units then convert to a $\mathrm{Ga}-\mathrm{NH}_{2}-\mathrm{Ga}$ linkage, as the $\mathrm{NH}_{3}$ of one unit hydrogenates the $-\mathrm{CH}_{3}$ group of the other unit, releasing $\mathrm{CH}_{4}$ as the by-product. During the $\mathrm{NH}_{3}$ pulse, such $\mathrm{Ga}-\mathrm{NH}_{2}-\mathrm{Ga}$ units (further abbreviated as $-\mathrm{NH}_{2}-$ ) concurrently form at various locations on the substrate, laterally propagating and increasing their surface coverage, ideally leading to the formation of a $\mathrm{GaN}$ monolayer.

Although the existence of the TMG: $\mathrm{NH}_{3}$ surface adduct is yet to be experimentally verified, one theoretical study on GaN MOCVD in fact uses the same surface adduct as proposed here (the so-called TCOM1(s) species in their work) to model the GaN formation by one out of the several explored pathways. ${ }^{72}$ Namely, the steps consist of (i) adsorption of TMG to a nitrogen site, (ii) adsorption of $\mathrm{NH}_{3}$ to the TMG, forming the surface adduct, and (iii) extraction of $\mathrm{CH}_{4}$ molecules from the adduct leading to $\mathrm{GaN}$ formation. The possibility of the existence of the surface adduct is further supported by an experimental study on the MOCVD reactions between TMG and $\mathrm{NH}_{3}$, which concludes that the formation of adducts takes place on or near the GaN growth surface. ${ }^{73}$ However, both referred works study MOCVD processes; therefore, the ashypothesized mechanism of the self-limiting growth of $\mathrm{GaN}$ by thermal ALD through the surface adduct route needs to be verified by appropriate surface analysis techniques. The latter is beyond the scope of this work.

\section{GAN MOCVD FROM TMG AND $\mathrm{NH}_{3}$}

In the absence of reports on the GaN ALD mechanism, this section briefly overviews the reactions occurring in $\mathrm{GaN}$ MOCVD, where the existence of the TMG: $\mathrm{NH}_{3}$ gas-phase adduct has been reported, and compares them with the surface adduct ALD model.

The MOCVD of GaN from TMG and $\mathrm{NH}_{3}$ is performed at substrate temperatures typically exceeding $900{ }^{\circ} \mathrm{C}$; the accepted gas-phase and surface reactions are shown in Figure 2. The pathway leading to the epitaxial growth is shown by the solid arrows. In this pathway, TMG decomposes into smaller units such as dimethylgallium $\left(\mathrm{Ga}\left(\mathrm{CH}_{3}\right)_{2}\right)$ and monomethyl- 


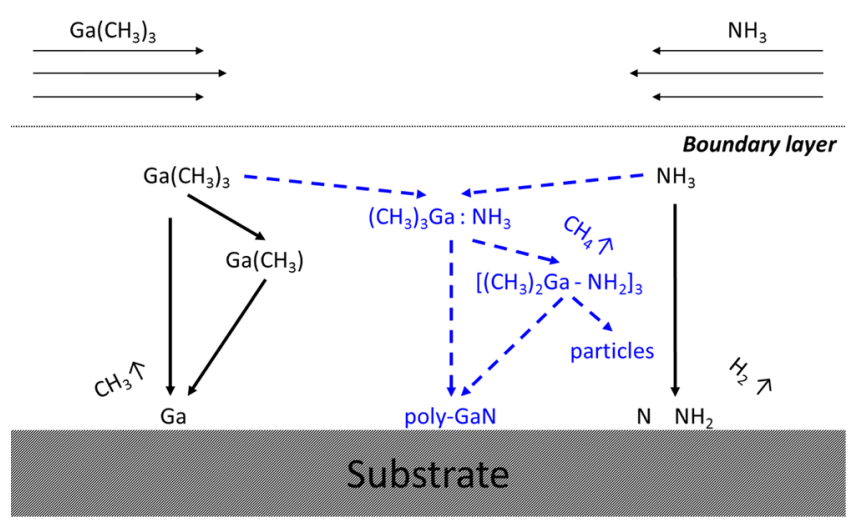

Figure 2. Simplified reaction schematic in GaN MOCVD, as compiled from several growth models (see text for references). The epi-GaN pathway and the adduct pathway are shown by solid and dashed arrows, respectively.

gallium $\left(\mathrm{GaCH}_{3}\right)$ already in the gas phase. ${ }^{72,74,75}$ As these species diffuse toward the substrate, their further decomposition leads to the formation of clusters of Ga. In parallel, $\mathrm{NH}_{3}$ dissociates on the substrate, forming $\mathrm{NH}_{x}(x=0-2)$ and $\mathrm{H}$ radicals. ${ }^{76,77}$ These radicals recombine with the Ga clusters (and/or DMG/TMG) on the substrate. Aided by the high substrate temperature, the products of the surface reactions possess sufficient mobility to migrate to energetically favorable surface sites, leading to crystalline $\mathrm{GaN}$ growth. ${ }^{78}$

A parallel set of gas-phase reactions, indicated by the dashed arrows in Figure 2, occurs away from the substrate at lower (a few hundred degrees) temperatures. The first reaction is the formation of the TMG: $\mathrm{NH}_{3}$ gas-phase adduct. ${ }^{79,80}$ The adduct tends to polymerize into larger clusters, which are amidic in nature, and has the form $\left(\left(\mathrm{CH}_{3}\right)_{2}-\mathrm{Ga}-\left(\mathrm{NH}_{2}\right)\right)_{n}$ or $\left(\left(\mathrm{CH}_{3}\right)_{3}-\right.$ $\left.\mathrm{Ga}:\left(\mathrm{NH}_{3}\right)_{n}\right) \cdot{ }^{81,82}$ These clusters can migrate toward the substrate or away from it. Migration toward the substrate is highly undesired in MOCVD growth as it results in polycrystalline $\mathrm{GaN}^{75}$ Moreover, the clusters can also introduce carbon contamination in the layer. Migration away from the substrate leads to further polymerization to eventually form particles up to several hundred nanometers in size. ${ }^{83,84}$ The particle formation can significantly deplete the precursor flux, thereby reducing the epi-GaN growth rate. ${ }^{84-86}$ Due to these issues, the adduct pathway is considered as parasitic in GaN MOCVD and therefore to be avoided. ${ }^{84}$

Several experimental ${ }^{57,79-82,87-91}$ and theoretical ${ }^{72,92-97}$ studies have been performed to investigate the reactions occurring in this pathway. As reported, electrostatic bonding between the Lewis acid (TMG) and the Lewis base $\left(\mathrm{NH}_{3}\right)$, forming the adduct, occurs with zero activation energy $\left(E_{\mathrm{A}}\right){ }^{97}$ The enthalpy of formation $(\Delta H)$ is reported between -15 and $-21 \mathrm{kcal} / \mathrm{mol}{ }^{57}$ The electrostatic bond is however not very strong (i.e., $\Delta H$ is low), making the reaction reversible (reaction 1). ${ }^{57}$ This in fact originates from a modest electronegativity difference between $\mathrm{Ga}(1.81)$ and $\mathrm{C}$ (2.55), ${ }^{98}$ causing the $\mathrm{Ga}-\mathrm{CH}_{3}$ bonds in the adduct to be less ionic and therefore making it difficult for $\mathrm{NH}_{3}$ to form an electrostatic bond with Ga. This in turn implies that the rate of the adduct formation can be suppressed by decreasing the partial pressure of the precursors and vice versa.

$$
\mathrm{Ga}\left(\mathrm{CH}_{3}\right)_{3}+\mathrm{NH}_{3} \rightleftharpoons \mathrm{Ga}\left(\mathrm{CH}_{3}\right)_{3}: \mathrm{NH}_{3}
$$

To compare with the gas-phase $\mathrm{Al}\left(\mathrm{CH}_{3}\right)_{3}: \mathrm{NH}_{3}$ adduct, the electrostatic bond of the latter is stronger $(\Delta H=-27 \mathrm{kcal} /$ $\mathrm{mol}) .^{81}$ This is due to the larger electronegativity difference between $\mathrm{Al}(1.61)$ and $\mathrm{C}(2.55) .{ }^{98}$ This shifts the equilibrium toward the adduct. ${ }^{81}$

Furthermore, the $\mathrm{Ga}\left(\mathrm{CH}_{3}\right)_{3}: \mathrm{NH}_{3}$ adduct can be irreversibly form the amidic $\left(\mathrm{CH}_{3}\right)_{2}-\mathrm{Ga}-\mathrm{NH}_{2}$ unit, through an intraadduct $\mathrm{H}$ transfer from $\mathrm{NH}_{3}$ to $-\mathrm{CH}_{3}$, liberating $\mathrm{CH}_{4}$ (reaction 2). ${ }^{85}$ The $E_{\mathrm{A}}$ of this reaction is $\sim 31 \mathrm{kcal} / \mathrm{mol} .{ }^{81}$ The further reactions of the adduct pathway are not considered for brevity.

$$
\mathrm{Ga}\left(\mathrm{CH}_{3}\right)_{3}: \mathrm{NH}_{3} \rightarrow\left(\mathrm{CH}_{3}\right)_{2}-\mathrm{Ga}-\mathrm{NH}_{2}+\mathrm{CH}_{4} \uparrow
$$

The as-presented GaN ALD model can therefore be viewed as the representation of the MOCVD adduct pathway on a surface in a pulsed-precursor deposition scheme. The equivalent of the TMG: $\mathrm{NH}_{3}$ gas-phase adduct is the hypothesized surface adduct. Similarly, the equivalent of the $\left(\mathrm{CH}_{3}\right)_{2}-\mathrm{Ga}-\mathrm{NH}_{2}$ amide is the $-\mathrm{NH}_{2}-$ surface linkage. The latter enables a low-temperature chemical route for GaN ALD.

\section{MODELING THE KINETICS OF GAN ALD}

The TMG: $\mathrm{NH}_{3}$ surface adduct formation is assumed to be reversible, similar to its gas-phase counterpart, because the same effects of electronegativity are expected to apply on the surface. The reversibility has also been theoretically assumed. ${ }^{72}$ This implies that, once physisorbed as an adduct, $\mathrm{NH}_{3}$ can desorb to the gas phase before forming the $-\mathrm{NH}_{2}-$ linkage. However, if the linkage is already formed, then it is assumed to be irreversible. It forms from the reaction of the $\mathrm{NH}_{3}$ group of one surface adduct unit with an adjacent $-\mathrm{CH}_{3}$ group of a chemisorbed TMG or that of the surface adduct species. For the TMA: $\mathrm{NH}_{3}$ surface adduct, such interactions have been reported. ${ }^{56}$

5.1. Kinetics of TMG: $\mathrm{NH}_{3}$ Surface Adduct Formation. During a $\mathrm{NH}_{3}$ pulse of duration $t_{\mathrm{NH}_{3}}$, adsorption of $\mathrm{NH}_{3}$ on the chemisorbed-TMG sites (equivalently, the adduct surface coverage $\theta$ ) can be expressed by Langmuir adsorptiondesorption kinetics (eq 3). ${ }^{99}$ In this equation, $\mathrm{C}_{\mathrm{NH}_{3}}$ is the $\mathrm{NH}_{3}$ concentration, and $k_{\mathrm{a}}$ and $k_{\mathrm{d}}$ are the rate constants of the $\mathrm{NH}_{3}$ adsorption and desorption, respectively. Equation 3 indicates that $\theta$ increases with both $t_{\mathrm{NH}_{3}}$ and $\mathrm{C}_{\mathrm{NH}_{3}}$; the latter can also be expressed via the $\mathrm{NH}_{3}$ partial pressure $\left(P_{\mathrm{NH}_{3}}\right)$.

$$
\theta\left(t_{\mathrm{NH}_{3}}\right)=k_{\mathrm{a}} C_{\mathrm{NH}_{3}} /\left(k_{\mathrm{a}} C_{\mathrm{NH}_{3}}+k_{\mathrm{d}}\right)\left[1-\mathrm{e}^{-\left(k_{\mathrm{a}} \mathrm{CHH}_{3}+k_{\mathrm{d}}\right) t_{\mathrm{NH}_{3}}}\right]
$$

The adduct coverage obtained from eq 3 as a function of $t_{\mathrm{NH}_{3}}$ and $P_{\mathrm{NH}_{3}}$, after assuming chemically reasonable values of $k_{\mathrm{a}}$ $\left(10^{-11} \mathrm{~cm}^{3} \mathrm{~s}^{-1}\right)$ and $k_{\mathrm{d}}\left(10^{6} \mathrm{~s}^{-1}\right)$ (e.g., $k_{\mathrm{a}}$ and $k_{\mathrm{d}}$ of the gasphase adduct reaction are determined to be $10^{-10} \mathrm{~cm}^{3} \mathrm{~s}^{-1}$ and $10^{8} \mathrm{~s}^{-1}$, respectively $\left.{ }^{100}\right)$, is shown in Figure 3a. As evident, $\theta$ stabilizes (i.e., indicating an equilibrium surface coverage) within a few microseconds of $t_{\mathrm{NH}_{3}}$. Changing the values of $k_{\mathrm{a}}$ and $k_{\mathrm{d}}$ over several orders of magnitude affects the time to reach the equilibrium. For instance, $k_{\mathrm{a}}=10^{-18} \mathrm{~cm}^{3} \mathrm{~s}^{-1}$ and $k_{\mathrm{d}}=$ $10^{-1} \mathrm{~s}^{-1}$ result in $10-20 \mathrm{~s}$. Such rate constants are however hardly physical. Furthermore, $\theta$ strongly depends on $P_{\mathrm{NH}_{3}}$, gradually approaching 1 at reasonably high $P_{\mathrm{NH}_{3}}$.

5.2. Kinetics of $-\mathrm{NH}_{2}-$ Linkage Formation. Since the surface adduct formation is presumably reversible, during a 

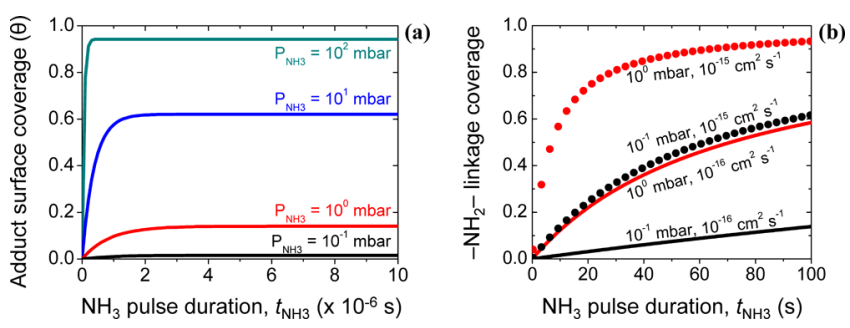

Figure 3. Simulated variation of (a) adduct surface coverage $(\theta)$ with the $\mathrm{NH}_{3}$ pulse duration $\left(t_{\mathrm{NH}_{3}}\right)$, under several $\mathrm{NH}_{3}$ partial pressures $\left(P_{\mathrm{NH}_{3}}\right)$. (b) Surface coverage of $-\mathrm{NH}_{2}-$ linkage with $t_{\mathrm{NH}_{3}}$ under $10^{-1}$ (black) and $10^{0} \mathrm{mbar}$ (red) $P_{\mathrm{NH}_{3}}$ at $10^{-16}$ (solid) and $10^{-15} \mathrm{~cm}^{2} \mathrm{~s}^{-1}$ (dotted) $k_{\mathrm{GaN}}$.

$\mathrm{NH}_{3}$ pulse, the physisorbed $\mathrm{NH}_{3}$ can either desorb from the TMG site or irreversibly form the $-\mathrm{NH}_{2}-$ linkage. In the first case, the TMG site is free to accept a new $\mathrm{NH}_{3}$ molecule. In the second case, this site can be excluded from participating in further reactions during this particular $\mathrm{NH}_{3}$ pulse.

These considerations were applied for simulating the $-\mathrm{NH}_{2}-$ coverage as a function of $t_{\mathrm{NH}_{3}}$ and $P_{\mathrm{NH}_{3}}$ (Figure $3 \mathrm{~b}$ ). Since the rate constant $\left(k_{\mathrm{GaN}}\right)$ for the adduct to $-\mathrm{NH}_{2}-$ conversion is not known empirically, it was varied between $10^{-15}$ and $10^{-16} \mathrm{~cm}^{2} \mathrm{~s}^{-1}$, as it yielded timescales of the same order as experimentally obtained for GPC (see Figure 4). As

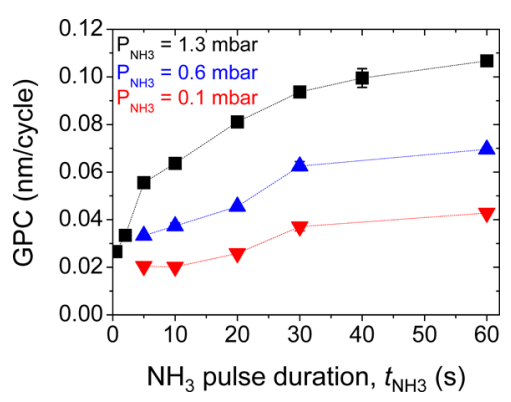

Figure 4. Variation of GPC with the $\mathrm{NH}_{3}$ pulse duration $\left(t_{\mathrm{NH}_{3}}\right)$ and the $\mathrm{NH}_{3}$ partial pressure $\left(P_{\mathrm{NH}_{3}}\right)$. The $P_{\mathrm{NH}_{3}}$ values correspond to total reactor pressures of 10 (black), 5 (blue), and $1 \mathrm{mbar}$ (red). The generic ALD recipe was $0.1 \mathrm{~s}$ TMG $/ 30 \mathrm{~s} \mathrm{Ar} / 1-60 \mathrm{~s} \mathrm{NH}_{3} / 60 \mathrm{~s}$ Ar. All depositions were performed at $400{ }^{\circ} \mathrm{C}$.

Figure $3 \mathrm{~b}$ shows, if $t_{\mathrm{NH}_{3}}$ is long (up to several minutes), all the adduct sites can be eventually converted to $-\mathrm{NH}_{2}-$ linkages. A complete $-\mathrm{NH}_{2}-$ coverage implies the formation of a $\mathrm{GaN}$ monolayer.

Figure $3 \mathrm{a}, \mathrm{b}$ further reveals the strong pressure dependence of the GaN ALD process. If the ALD is performed at low $P_{\mathrm{NH}_{3}}$, this would result in low $\theta$ (Figure $3 \mathrm{a}$ ). In such a situation, a very long $t_{\mathrm{NH}_{3}}$ would eventually convert all the adduct units to $-\mathrm{NH}_{2}-$ linkages. On the contrary, ALD performed under high $P_{\mathrm{NH}_{3}}$ would already initially result in large $\theta$, therefore requiring a shorter $t_{\mathrm{NH}_{3}}$ to achieve a high $-\mathrm{NH}_{2}-$ coverage. In the next section, we shall experimentally validate this behavior.

\section{EXPERIMENTAL RESULTS ON THERMAL GAN ALD}

6.1. ALD Window. Figure 4 shows the variation of GPC with $t_{\mathrm{NH}_{3}}$ and $P_{\mathrm{NH}_{3}}$ monitored by in situ SE. The generic ALD recipe can be found in the caption. Long Ar purges were kept to minimize possible gas-phase reactions. This is important as the pressure is significantly higher than typically used for ALD. Besides, the Ar flow rate ensured three times change of the reactor volume every second.

The strong dependence of GPC on both $t_{\mathrm{NH}_{3}}$ and $P_{\mathrm{NH}_{3}}$ is visible in Figure 4. Needless to say, the latter is the most important feature of this ALD process. For every $P_{\mathrm{NH}_{3}}$, the GPC hardly shows saturation even at long $t_{\mathrm{NH}_{3}}(30,60 \mathrm{~s})$; instead, it shows a slow increase. This can be explained by the ongoing surface reactions involving adduct and $-\mathrm{NH}_{2}-$ linkage formation, as long as the $\mathrm{NH}_{3}$ pulse continues (recall Figure $3 \mathrm{~b}$ ). Limited by the current maximum allowable reactor pressure $(10 \mathrm{mbar})$ and due to concerns of $\mathrm{NH}_{3}$ removal during purging at the high pressures, depositions under higher $P_{\mathrm{NH}_{3}}$ or $t_{\mathrm{NH}_{3}}$ were not performed in this first study. However, it would be interesting to verify whether the GPC can reach a regime independent of the two parameters. As discussed in the previous section, the coverage of the $-\mathrm{NH}_{2}-$ linkages is dependent on both $P_{\mathrm{NH}_{3}}$ (though the coverage of the surface adduct $(\theta)$ ) and $t_{\mathrm{NH}_{3}}$ (through the conversion of the adduct). A high $P_{\mathrm{NH}_{3}}$ would already ensure high $\theta$, and therefore, the GPC saturation would already occur at low $t_{\mathrm{NH}_{3}}$. Extending the simulated $-\mathrm{NH}_{2}-$ coverage to higher $t_{\mathrm{NH}_{3}}$ and $P_{\mathrm{NH}_{3}}$ (Figure S2) shows this; the saturation of the $-\mathrm{NH}_{2}-$ coverage implies the formation of a $\mathrm{GaN}$ monolayer. Whether monolayer growth can be achieved in practice or the determination of the maximum achievable GPC for this process can be for a future study.

Varying the TMG pulse duration at different $P_{\mathrm{NH}_{3}}(1,10$ mbar) hardly affects the GPC (Figure S3a). This indicates that even the shortest TMG pulse is sufficient to complete the surface coverage. This can be explained by the high vapor pressure of TMG (>200 mbar) at a storage temperature of 18 ${ }^{\circ} \mathrm{C}$. Varying the post-TMG purge duration hardly affects the GPC as well (Figure S3b).

The variation of GPC with the deposition temperature is shown in Figure 5. Hardly any growth occurs at or below 350

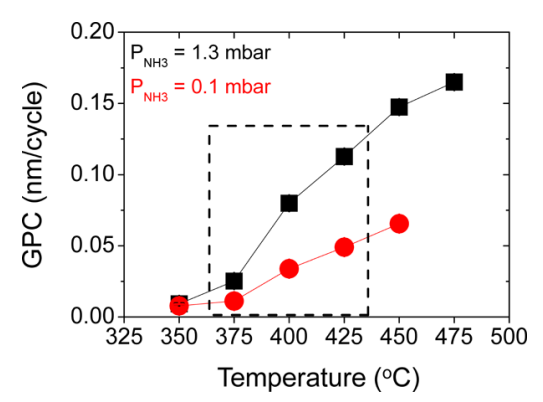

Figure 5. Variation of GPC with the deposition temperature and $P_{\mathrm{NH}_{3}}$. The ALD recipe was $0.1 \mathrm{~s}$ TMG/30 s Ar/30 s NH$/ 60 \mathrm{~s} \mathrm{Ar}$. The box indicates the temperature range where carbon-free GaN layers were deposited.

${ }^{\circ} \mathrm{C}$. In terms of the ALD model, this indicates the inefficacy of the adduct to $-\mathrm{NH}_{2}-$ conversion at such temperatures. Beyond $350{ }^{\circ} \mathrm{C}$, the GPC steadily increases, with a higher rate at a higher $P_{\mathrm{NH}_{3}}$. At both pressures, no temperature window exists with a (near-to) constant GPC. According to the XPS results (Section 7), the deposition of carbon-free $\mathrm{GaN}$ is 

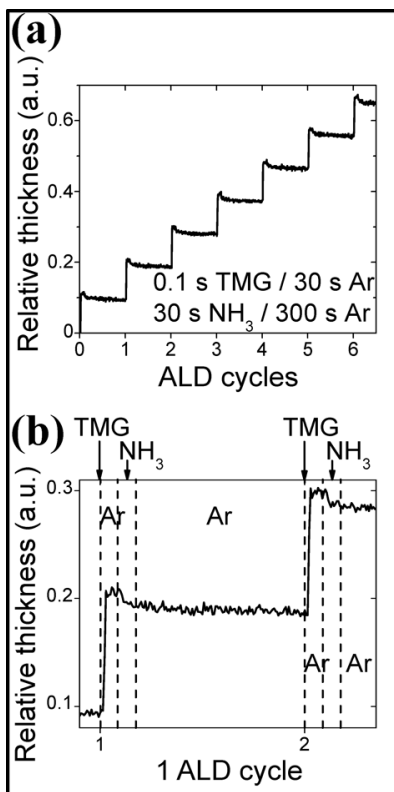

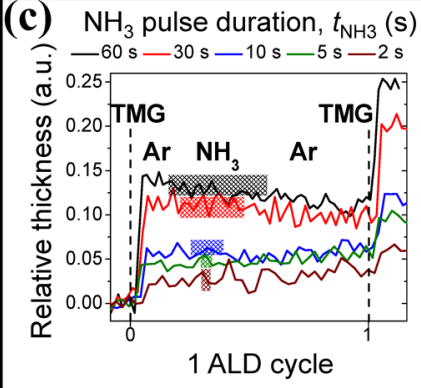

(d)

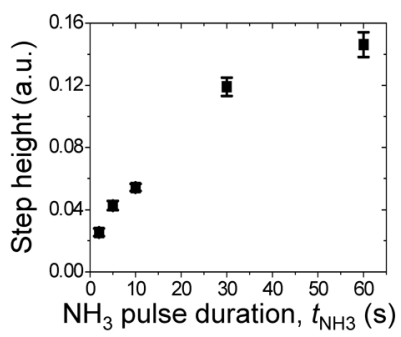

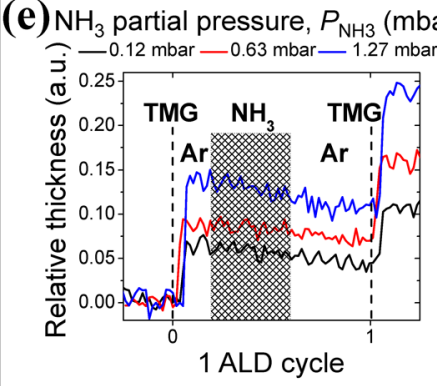

(f)

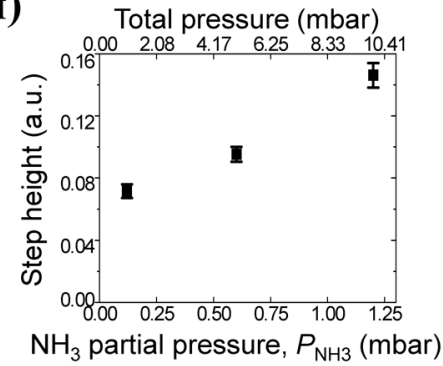

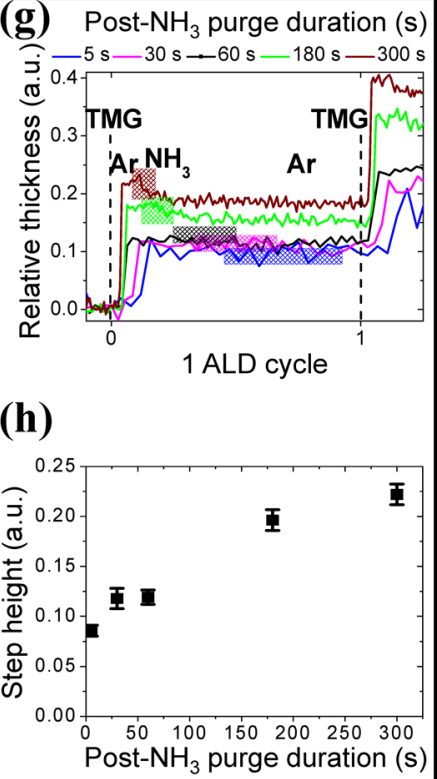

Figure 6. Monitoring GaN growth by in situ SE. (a) Stepwise growth in every ALD cycle. (b) Zoom-in on a single ALD cycle, showing the instants and durations of precursors and purges. (c,e,g) Influence of $t_{\mathrm{NH}_{3}}, P_{\mathrm{NH}_{3}}$, and post- $\mathrm{NH}_{3}$ purge duration on the shape of ALD pulses. For each case, the abscissa has been normalized with respect to the cycle time, and the duration of the precursors and purges are shown; the $\mathrm{NH}_{3}$ pulse duration is represented by the shaded regions. (d,f,h) Quantification of the step heights corresponding to panels (c), (e), and (g), respectively. Their means and standard deviations were obtained from several steps at each setting, whereas only a representative step at each setting is shown in panels (c), (e), and (g).

possible only within a narrow temperature range, approximately between 375 and $425{ }^{\circ} \mathrm{C}$ (Figure 5, boxed). Beyond $425^{\circ} \mathrm{C}$, thermal decomposition of TMG results in increasing amounts of carbon and gallium in the layers, with their contents being dependent on both temperature and pressure. ${ }^{53}$

Unexpectedly (and rather atypically for an ALD process), the GPC increases with the post- $\mathrm{NH}_{3}$ purge duration (Figure S4a). An opposite trend is usually observed in ALD; that is, the GPC increases at short purge durations due to gas-phase reactions additionally contributing to the layer growth. At long purge durations, when the gas-phase components are sufficiently depleted, the GPC stabilizes. For instance, for GaN films prepared by plasma-enhanced ALD with $\mathrm{NH}_{3}$ plasma, ${ }^{30}$ the GPC indeed shows the expected behavior (Figure S4b). However, for thermal GaN ALD explored here, this is clearly not the case.

We explain this anomalous behavior by the high sticking coefficient of $\mathrm{NH}_{3}$ to the stainless steel reactor surface. ${ }^{101}$ In our separate work, the kinetics of the $\mathrm{NH}_{3}$ removal from a cold-wall reactor was studied by in situ absorption spectroscopy. ${ }^{102}$ The $\mathrm{NH}_{3}$ concentration decayed indeed slowly. From an initial $P_{\mathrm{NH}_{3}}$ of $0.15 \mathrm{mbar}$, it was $0.01 \mathrm{mbar}$ even after 10 min. In this work, a hot-wall reactor is used; therefore, a higher outgassing rate can be expected. However, the $P_{\mathrm{NH}_{3}}$ values are also 2 to 3 orders higher. Therefore, the residual $\mathrm{NH}_{3}$ during purging presumably contributes to the GPC increase.

Moreover, surface reactions in the form of adduct to $-\mathrm{NH}_{2}-$ conversion can contribute to the GPC rise, even after $P_{\mathrm{NH}_{3}}$ has reduced. Since the conversion demands first the formation of adjacent adduct units and, second, the alternate arrangement of the $-\mathrm{CH}_{3}$ and $\mathrm{NH}_{3}$ groups of these units, satisfying these requirements can make the conversion slow.

6.2. Growth Analysis by In Situ SE. The ALD mechanism is studied further by in situ monitoring of the layer growth with SE and focusing on the shape of the growth curve. Since the deposition is performed by alternate precursor pulses and purges, the layer growth occurs through clear welldefined steps (Figure 6a). The steps correspond to the introduction of one of the precursors. In an earlier study on the ALD of AlN, the step at the beginning of each ALD cycle followed the introduction of TMA. ${ }^{55}$ For GaN ALD, the step follows the introduction of TMG and presumably its successful chemisorption. The $\mathrm{NH}_{3}$ pulse, in contrast, does not cause a step but leads to a gentle "thickness" decrease. Figure $6 \mathrm{~b}$ zooms into a single ALD cycle, showing the instants of the precursor pulses and purges. During the post-TMG Ar purge, hardly any thickness variation is observed, as expected.

The extremely small thickness variations within an ALD cycle (Figure 6b) are in fact the optical signal changes, interpreted by the SE model in this manner. In addition to the actual thickness variations (we cannot exclude this), changes in the optical properties of the surface upon the corresponding chemical reactions can also cause this effect. ${ }^{55}$ For example, the chemisorption of TMG and its nitridation into the $-\mathrm{NH}_{2}-$ links can cause the optical changes. The starting and ending points of each cycle correspond to the real thickness values, giving the overall thickness increase per cycle, interpreted as the GPC. The film thickness (and therefore the GPC) is always verified by other ex situ measurement techniques (e.g., SEM, TEM). A variation of thickness within a cycle, however, cannot be guaranteed, as explained above.

6.2.1. Effect of $\mathrm{N}_{\mathrm{NH}_{3}}$ on Step Height. Figure 6c compares the shapes of individual ALD pulses obtained by SE for different $t_{\mathrm{NH}_{3}}$. The corresponding step-height increase is further quantified in Figure $6 \mathrm{~d}$. The gradual increase presumably indicates enhancement of TMG chemisorption with $t_{\mathrm{NH}_{3}}$. This can be explained by a higher surface coverage of $-\mathrm{NH}_{2}-$ linkages (recall Figure $3 \mathrm{~b}$ ) after a long $t_{\mathrm{NH}_{3}}$. These linkages act 

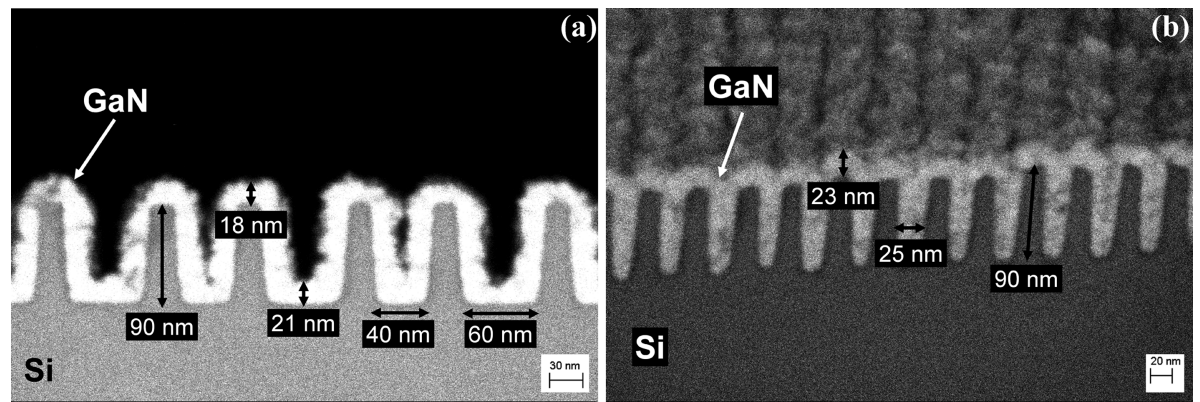

Figure 7. HR-ESB images of GaN layers showing (a) decent conformality and (b) trench-filling capability. The layer was deposited with the ALD recipe $0.1 \mathrm{~s} \mathrm{TMG} / 30 \mathrm{~s} \mathrm{Ar} / 30 \mathrm{~s} \mathrm{NH} / 60 \mathrm{~s} \mathrm{Ar}$ at $400{ }^{\circ} \mathrm{C}$ and $1.3 \mathrm{mbar} P_{\mathrm{NH}_{3}}$.

as sites for TMG chemisorption in the next cycle, increasing the surface coverage of the chemisorbed TMG and thus resulting in a larger step. On the contrary, shorter $t_{\mathrm{NH}_{3}}$ leads to lower $-\mathrm{NH}_{2}-$ coverage. Therefore, parts of the surface still remain terminated by the $-\mathrm{CH}_{3}$ groups from previous TMG exposures. A weaker step is recorded as a result.

6.2.2. Effect of $P_{\mathrm{NH}_{3}}$ on Step Height. The same mechanism comes into play when $P_{\mathrm{NH}_{3}}$ is increased (Figure 6e,f). A higher $P_{\mathrm{NH}_{3}}$ causes a more efficient nitridation of the TMGchemisorbed surface, leading to a higher coverage of $-\mathrm{NH}_{2}-$ linkages. This increases the surface coverage of chemisorbed TMG and results in larger steps.

6.2.3. Effect of Post- $\mathrm{NH}_{3}$ Purge Duration on Step Height. The dependence of GPC on the post- $\mathrm{NH}_{3}$ purge duration is reflected in the increasing step height (Figure $6 \mathrm{~g}$ ). Longer purges increase the $-\mathrm{NH}_{2}-$ coverage, creating sites for the subsequent TMG chemisorption. Figure 6 h shows a saturating trend of the step height at very long purges $(180,300 \mathrm{~s})$. This implies that either the formation of $-\mathrm{NH}_{2}-$ approaches completion or $P_{\mathrm{NH}_{3}}$ becomes too low to sustain this reaction. The former implies the progression toward a monolayer of $\mathrm{GaN}$, especially because the step heights at 180 and $300 \mathrm{~s}$ are greater than at maximum $t_{\mathrm{NH}_{3}}$ or $P_{\mathrm{NH}_{3}}$ (Figure 6d,f).

6.2.4. Evolution of Step Height at the Various Stages of $A L D$. Revisiting Figure S1, in the first $\sim 100$ cycles, the GPC is almost negligible. In this so-called "incubation period", the step heights are extremely low (practically nonexistent, see inset S1i) and reflects a consequently extremely low surface coverage of chemisorbed TMG. The low surface coverage may be ascribed to the $\mathrm{H}$ termination of the $\mathrm{Si}(111)$ substrate (formed after the precleaning), which may not be favorable toward the TMG chemisorption. The tendency of TMG to dissociate at the used deposition temperature $\left(400{ }^{\circ} \mathrm{C}\right)$ can further aggravate its chemisorption, additionally contributing to the long incubation stage. The low surface coverage in turn leads to a low coverage of the $-\mathrm{NH}_{2}-$ linkages, and sparsely populated $\mathrm{GaN}$ and $\mathrm{Ga}$ clusters are speculated to form at this stage, the confirmation of which may be subject to a future study.

With progression of the ALD (from 100 to $\sim 250$ cycles), as TMG starts to chemisorb on the preformed $\mathrm{Ga}$ and $\mathrm{GaN}$ clusters (as well as on the other unoccupied areas of the substrate), its surface coverage increases, as reflected from the step heights becoming prominent and increasing in magnitude (see insets S1-ii,iii).

Finally, the attainment of stable (i.e., unchanging) step heights beyond 250 ALD cycles (see inset S1-iv) implies a constant coverage of chemisorbed TMG and $-\mathrm{NH}_{2}-$ linkages at every cycle that supports self-limiting growth of the layer.

\section{CHARACTERIZATION OF ALD GAN LAYERS}

7.1. SEM Analysis. Figure 7a,b shows HR-ESB images of thermal ALD GaN layers deposited in Si trenches, used for testing the conformality and trench-fill performance obtained from the ALD recipe (see caption). To investigate the apparent roughness of the layer in the two images, a layer deposited in the same run on a precleaned $\mathrm{Si}(111)$ substrate was analyzed using atomic force microscopy (AFM). The root mean square (RMS) value of the roughness is $1.90 \pm 0.20 \mathrm{~nm}$.

7.2. GIXRD and HRTEM Analyses. The polycrystalline structure is observed from HRTEM imaging (Figure 8, top), which reveals crystalline domains oriented in different directions. This sample was prepared on an in situ deposited ALD AlN buffer-layer. The domain sizes, indicated by arrows, are sub-10 nm. Fast Fourier transform (FFT) analysis at several domains (one of such domains is enclosed by a yellow box; its FFT is shown in the inset) reveals a $d$ spacing of 2.60 $\pm 0.02 \AA$. This conforms to the (002) wurtzitic GaN crystal planes.

The sample used for the GIXRD was deposited on a $\mathrm{Si}(111)$ substrate using short, instead of long, $\mathrm{NH}_{3}$ pulse times (10 s) and purge times $(4 \mathrm{~s} \text { each })^{52}$ in order to expedite the deposition and grow a suitably thick layer $(35 \mathrm{~nm})$ for GIXRD. The rest of the process parameters were unchanged. (To note, the sample used for HRTEM was not used for GIXRD owing to the possible overlap of diffraction peaks from AlN and GaN.) The formation of polycrystalline $\mathrm{GaN}$ was confirmed from GIXRD, acquired at an incident angle $(\omega)$ of $1^{\circ}$ (Figure 8 , bottom). The peaks correspond to hexagonal wurtzitic $\mathrm{GaN}$, as indicated by the blue bars (COD No. 9011658). The $d$ spacings of the (100), (002), and (101) crystal planes are estimated to be $2.8,2.6$, and $2.5 \AA$, respectively, which agrees with those reported in the database. The average grain size of the (002) crystal planes, estimated using the Panalytical HighScore Plus software, is revealed to be $3.4 \mathrm{~nm}$. Both GIXRD and HRTEM hence confirm the formation of polycrystalline wurtzitic GaN layers with sub-10 nm grains, with either ALD recipes and substrates.

7.3. FTIR Analysis. The FTIR transmission spectrum of the layer, prepared with the short $\mathrm{NH}_{3}$ pulses and purges, is shown in Figure S5. The spectrum is the ratio of the single beam transmittance spectra of the GaN sample and of a reference $\mathrm{Si}$ wafer. The principle absorption at $534 \mathrm{~cm}^{-1}$ corresponds to the $\mathrm{Ga}-\mathrm{N}$ stretching mode, in excellent agreement with that in wurtzitic $\mathrm{GaN}$ films reported at 533 $\mathrm{cm}^{-1} .{ }^{103}$ The absorptions due to the $-\mathrm{NH}_{2}$ bending and 


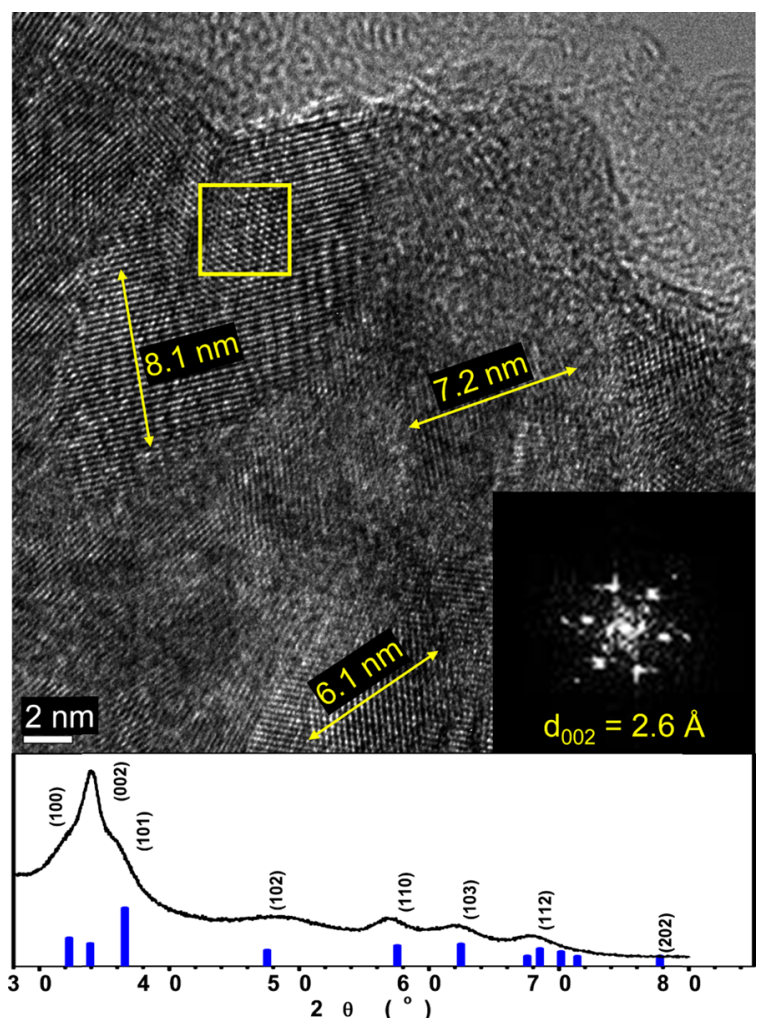

Figure 8. (top) HR-TEM image showing the polycrystalline structure with sub-10 nm domains. Inset: FFT analysis of a domain (in yellow box) reveals a $d$ spacing of $2.6 \AA$, consistent with wurtzitic (002) GaN crystal planes. (bottom) GIXRD scan revealing the polycrystalline wurtzitic structure of the layer. The blue bars represent the peak positions for wurtzitic GaN. The parentheses denote the Miller indices.

stretching modes were also identified at 945 and $3250 \mathrm{~cm}^{-1}$, respectively. ${ }^{104}$ These absorptions suggest that the growth mechanism could indeed have involved $-\mathrm{NH}_{2}-$ linkages, and some of these linkages did not react with TMG. The evidence of some residual hydrogen is seen from the absorption at 704 $\mathrm{cm}^{-1}$, corresponding to the $\mathrm{Ga}-\mathrm{H}$ bending vibration. ${ }^{104}$ The absorption at $1110 \mathrm{~cm}^{-1}$ corresponds to $\mathrm{Si}-\mathrm{O}$ bonds, originating from the native oxide on the wafer. The overshoot between 2000 and $2500 \mathrm{~cm}^{-1}$ originates from small variations in the $\mathrm{CO}_{2}$ level in the spectrometer between the measurements.

7.4. XPS Analysis. The layer composition and the bonding environment were studied with XPS, employing an $\mathrm{Al} \mathrm{K} \alpha$ monochromatic X-ray source. Sputtering with $2 \mathrm{kV} \mathrm{Ar}^{+}$ions was performed to obtain the depth profile composition. Lowenergy electrons and $\mathrm{Ar}^{+}$ions were additionally used to neutralize the sample during the depth profiling. The surface carbon $\mathrm{C} 1 \mathrm{~s}$ peak at $284.8 \mathrm{eV}$, originating from the adventitious carbon contamination, ${ }^{105}$ was used to calibrate the peak positions. All spectra were deconvoluted by single or multiple Gaussian-Lorentzian bands, after assuming an iterated-Shirley background.

Figure 9a shows the depth profile composition of a $14 \mathrm{~nm}$ thick layer, prepared using long $\mathrm{NH}_{3}$ pulses $(30 \mathrm{~s})$ and purges $(30,60 \mathrm{~s})$, on $\mathrm{Si}$. XPS reveals that the layer is not stoichiometric but rather rich in Ga. A modest level of oxygen and hardly any carbon are detected. The average composition is estimated as $\mathrm{Ga}_{0.53} \mathrm{~N}_{0.39} \mathrm{C}_{0.01} \mathrm{O}_{0.07}$. The origin of oxygen is
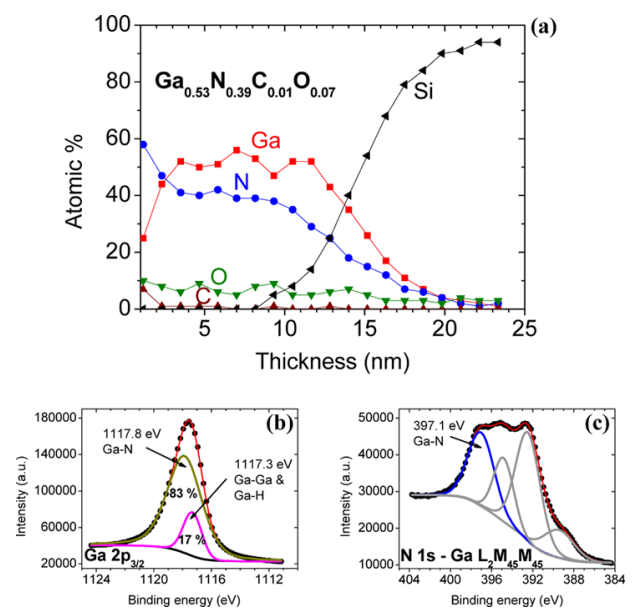

Figure 9. (a) Sputter-depth-profiled XPS composition of the layer deposited on $\mathrm{Si}$. The average composition is indicated in the figure. (b) Photoelectron Ga $2 \mathrm{p}_{3 / 2}$ spectrum and (c) photoelectron $\mathrm{N} 1 \mathrm{~s}-$ Auger $\mathrm{Ga}_{2} \mathrm{M}_{45} \mathrm{M}_{45}$ spectra from the layer bulk. They have been deconvoluted to reveal the various chemical bonds.

ascribed to the base pressure $\left(10^{-7} \mathrm{mbar}\right)$ of the reactor and purity of the precursor and carrier gases.

To understand the origin of the nonstoichiometric composition, the chemical bonding inside the layer was analyzed, focusing on the photoelectron $\mathrm{Ga} 2 \mathrm{p}_{3 / 2}$ spectrum (Figure $9 \mathrm{~b}$ ) and the photoelectron $\mathrm{N} 1 \mathrm{~s}-$ Auger $\mathrm{Ga} \mathrm{L}_{2} \mathrm{M}_{45} \mathrm{M}_{45}$ complex (Figure 9c). (To note, when an $\mathrm{Al} \mathrm{K} \alpha 1486.6 \mathrm{eV}$ Xray source is used, the $\mathrm{N} 1 \mathrm{~s}$ spectrum is partially overlapped by the triplet $\mathrm{Ga}_{2} \mathrm{M}_{45} \mathrm{M}_{45}$ Auger bands. ${ }^{106}$ Deconvolution of the complex yielded the $\mathrm{N}$ 1s band (in blue) at $397.1 \mathrm{eV}$ binding energy (BE) and the Auger triplet (in grey) at lower $\mathrm{BE}$. The $\mathrm{N}$ 1s BE agrees well with the literature-reported $\mathrm{BE}$ of $\mathrm{N}-\mathrm{Ga}$ bonds $(396.9 \mathrm{eV})$ in poly-GaN films. ${ }^{39}$

Whereas the Ga $2 p_{3 / 2}$ spectrum of a perfectly stoichiometric GaN layer should allow fitting only by one GaussianLorentzian band (i.e., signifying only one type of bonding environment: $\mathrm{Ga}-\mathrm{N}$ ), the spectrum of Figure $9 \mathrm{~b}$ is best deconvoluted by two bands, suggesting at least two bonding environments of $\mathrm{Ga}$ in the layer. The major band at $1117.8 \mathrm{eV}$, occupying $83 \%$ of the peak area, corresponds to the $\mathrm{Ga}-\mathrm{N}$ bond due to an excellent match with the reported $\mathrm{BE}$ of $1117.8^{107}$ or $1117.9 \mathrm{eV}^{108}$ The minor band at $1117.3 \mathrm{eV}$, occupying the remaining area, implies additional bonding environments of $\mathrm{Ga}$.

From the depth profile composition and possibly from FTIR, the relevant candidates for the minor band are $\mathrm{Ga}-\mathrm{Ga}$, $\mathrm{Ga}-\mathrm{O}$, and $\mathrm{Ga}-\mathrm{H}$ bonds. Based on the electronegativity differences between $\mathrm{Ga}, \mathrm{H}, \mathrm{N}$, and $\mathrm{O}(1.81,2.20,3.04$, and 3.44 , respectively), ${ }^{98}$ the $\mathrm{Ga}-\mathrm{O}$ bond is expected at a higher $\mathrm{BE}$ than the $\mathrm{Ga}-\mathrm{N}$ bond. ${ }^{109}$ Indeed, it has been reported at a $1.3 \mathrm{eV}$ higher $\mathrm{BE}$ than the $\mathrm{Ga}-\mathrm{N}$ bond. ${ }^{110}$ However, since the oxygen content in the layer is rather modest, the band is submerged under the strong $\mathrm{Ga}-\mathrm{N}$ band. The remaining candidates are $\mathrm{Ga}-\mathrm{Ga}$ and $\mathrm{Ga}-\mathrm{H}$ bonds. The reported $\mathrm{BE}$ of the former is $1116.5 \mathrm{eV}^{53,111}$ while the latter is expected around $1 \mathrm{eV}$ lower than the $\mathrm{Ga}-\mathrm{N} \mathrm{BE}^{112}$ and therefore around $1116.8 \mathrm{eV}$ in our layer. The minor band, peaked at $1117.3 \mathrm{eV}$, may be ascribed to the contribution from both these bonds. Although at a very similar $\mathrm{BE}$, the occurrence of the $\mathrm{Ga}-\mathrm{C}$ bond $\left(1117.2 \mathrm{eV}^{71}\right)$ is ignored due to the ultralow $\mathrm{C}$ content (Figure 9a). Finer deconvolution between $\mathrm{Ga}-\mathrm{Ga}$ and $\mathrm{Ga}-\mathrm{H}$ 
bonds was not attempted because the measurement was limited by the instrumental resolution of $0.4 \mathrm{eV}$.

The origin of the $\mathrm{Ga}$ richness of the layer, even though grown in a self-limiting fashion, demands an investigation. The known phenomenon of preferential sputtering of $\mathrm{N}$ over $\mathrm{Ga}$ during depth profiling of $\mathrm{GaN}^{107}$ may not be the cause since that would cause only a minor $\left(2-3\right.$ at \%) excess of Ga. ${ }^{53}$ It is more likely that, during the growth, not all chemisorbed TMG sites had converted into $\mathrm{GaN}$, that is, either the adduct formation had not occurred or the adduct had not converted into $-\mathrm{NH}_{2}-$ linkages. The simultaneous thermal dissociation of the TMG cannot be ignored at the current deposition temperature $\left(400{ }^{\circ} \mathrm{C}\right)$, resulting in partial/complete $-\mathrm{CH}_{3}$ detachment. ${ }^{71}$ The dissociated species may not be expected to participate in the adduct formation owing to their lack of $-\mathrm{CH}_{3}$ ligands. These would instead accumulate as Ga clusters, causing the Ga richness of the layer, as observed. Increasing the deposition temperature enhances the formation of these clusters. ${ }^{53}$ The longer (purge, pulse) duration may additionally enhance the $\mathrm{Ga}$ richness since the (presumably slow) thermal decomposition of chemisorbed TMG is an ongoing process.

The means to more efficiently nitridize the chemisorbed TMG is to further increase $P_{\mathrm{NH}_{3}}$ and/or $t_{\mathrm{NH}_{3}}$. However, the former can be a limitation in most reactor designs and can also introduce contaminants like oxygen when the precursor and/or carrier gases are not sufficiently purified. Increasing $P_{\mathrm{NH}_{3}}$ by the reactor pressure proportionally increases the partial pressure of oxidants, enhancing the rate of surface oxidation. Increasing $t_{\mathrm{NH}_{3}}$ can (i) pose impractically long cycle times and (ii) increase the Ga richness. Practically, using short cycle times (especially reducing the purge times), even at the risk of venturing outside true ALD conditions, allows us to minimize the extent of TMG dissociation at every cycle. Indeed, shortening the purge duration from 30 and $60 \mathrm{~s}$ to only $4 \mathrm{~s}$ each resulted in a nearly stoichiometric composition of $\mathrm{Ga}_{0.46} \mathrm{~N}_{0.44} \mathrm{C}_{0.02} \mathrm{O}_{0.08}$.

\section{CONCLUSIONS}

In this paper, we have shown that low-temperature thermal ALD of polycrystalline GaN layers from TMG and $\mathrm{NH}_{3}$ is possible without cracking the $\mathrm{NH}_{3}$ into radicals. Carbon-free $\mathrm{GaN}$ layers were grown between 375 and $425^{\circ} \mathrm{C}$ with a GPC of $0.1 \mathrm{~nm} /$ cycle.

In order to achieve this, based on the pre-reported role of the TMA: $\mathrm{NH}_{3}$ surface adduct in AlN ALD and the role of the TMG: $\mathrm{NH}_{3}$ gas-phase adduct in GaN MOCVD, we hypothesized the existence of an analogous TMG: $\mathrm{NH}_{3}$ surface adduct facilitating the GaN ALD. The proposed ALD model involved (i) the reversible formation of the TMG: $\mathrm{NH}_{3}$ surface adduct upon the physisorption of $\mathrm{NH}_{3}$ on a TMG-chemisorbed surface site and (ii) the interaction between the $-\mathrm{CH}_{3}$ and the $\mathrm{NH}_{3}$ groups of neighboring adduct units, leading to the irreversible formation of a $\mathrm{Ga}-\mathrm{NH}_{2}-\mathrm{Ga}$ linkage. The ALD mechanism could also be viewed as the replication of the adduct pathway, prevalent in GaN MOCVD, into equivalent surface reactions.

The kinetics of the reversible surface adduct formation and its irreversible conversion into $-\mathrm{NH}_{2}-$ linkage was simulated. The results showed that, whereas the surface coverage of the adduct was primarily dependent on the $\mathrm{NH}_{3}$ partial pressure, the linkage formation was strongly dependent on the $\mathrm{NH}_{3}$ pulse duration. The experimental observation of the strong
GPC dependence on both these parameters supported the simulations. The pressure dependence was indeed the novelty of this ALD process - the key to grow GaN thermally.

The stepwise growth of the layer, monitored by in situ SE, supplemented the ALD model. Increasing the $\mathrm{NH}_{3}$ pulse duration, the partial pressure, and the post- $\mathrm{NH}_{3}$ purge duration resulted in higher thickness steps following the TMG pulse. This indicated a higher surface coverage of $-\mathrm{NH}_{2}-$ and hence chemisorbed TMG after the subsequent TMG pulse due to the longer durations and higher $P_{\mathrm{NH}_{3}}$.

Ex situ layer characterization revealed (i) good conformality and trench-filling performance (from SEM), (ii) polycrystalline wurtzitic structure with sub-10 nm grains (from GIXRD and TEM), (iii) evidence of residual $-\mathrm{NH}_{2}$ bonds (from FTIR), and (iv) an average layer stoichiometry of $\mathrm{Ga}_{0.53} \mathrm{~N}_{0.39} \mathrm{C}_{0.01} \mathrm{O}_{0.07}$, implying a Ga-rich layer, with evidence of $\mathrm{Ga}-\mathrm{Ga}$ chemical bonds (from XPS). The reason behind the excess Ga was attributed to the ongoing partial decomposition of the TMG at an ALD temperature of $400{ }^{\circ} \mathrm{C}$, at the sites where the $-\mathrm{NH}_{2}-$ linkage formation had not occurred. Shortening the long cycle times at the risk of processing outside the ALD window resulted in a nearly stoichiometric composition of $\mathrm{Ga}_{0.46} \mathrm{~N}_{0.44} \mathrm{C}_{0.02} \mathrm{O}_{0.08}$. The negligible carbon content in the layers proved that a radical-assisted route was not necessary to extract the $-\mathrm{CH}_{3}$ groups of TMG to form GaN; the surface adduct pathway efficiently ensured this.

To conclude, the self-limiting nature of the adduct to $-\mathrm{NH}_{2}-$ linkage conversion does imply an ALD process. However, the absence of a $\mathrm{GPC}-t_{\mathrm{NH}_{3}}$ saturation regime implies otherwise. The demonstrated pressure dependence of the growth kinetics is also atypical for ALD. In the absence of a dedicated surface study, this work can neither prove the existence of the surface adduct nor validate the proposed ALD model. However, both can adequately explain the experimental observations.

\section{ASSOCIATED CONTENT}

\section{S Supporting Information}

The Supporting Information is available free of charge on the ACS Publications website at DOI: 10.1021/acs.jpcc.9b05946.

Additional results pertaining to in situ monitoring of the GPC evolution with ALD cycles (Figure S1), the simulated surface coverage of $-\mathrm{NH}_{2}-$ linkages at high $P_{\mathrm{NH}_{3}}$ and $t_{\mathrm{NH}_{3}}$ values (Figure S2), the variation of GPC with the TMG pulse duration and the post-TMG purge duration (Figure S3), the variation of GPC with the post- $\mathrm{NH}_{3}$ purge duration in thermal ALD and PEALD processes (Figure S4), and the FTIR transmission spectrum of thermal ALD GaN layer (Figure S5) (PDF)

\section{AUTHOR INFORMATION}

\section{Corresponding Author}

*E-mail: a.y.kovalgin@utwente.nl. Phone: +31 534892841.

\section{ORCID}

Sourish Banerjee: 0000-0002-4124-7881

\section{Author Contributions}

The manuscript was written through contributions of all authors. All authors have given approval to the final version of the manuscript. 


\section{Notes}

The authors declare no competing financial interest.

\section{ACKNOWLEDGMENTS}

The authors thank G. A. M. Kip, M. A. Smithers, E. G. Keim, and K. M. Batenburg (MESA+ Institute for Nanotechnology) for helping with the film characterization and Prof. Gertjan Koster and Prof. Jurriaan Huskens (University of Twente) for the use of their XRD and FTIR setups. This work has been financially supported by The Netherlands Organization for Scientific Research (NWO), Domain Applied and Engineering Sciences, project 13145 .

\section{REFERENCES}

(1) Suzuki, M.; Uenoyama, T.; Yanase, A. First-Principles Calculations of Effective-Mass Parameters of AlN and GaN. Phys. Rev. B 1995, 52, 8132.

(2) Lakshmi, E. Dielectric Properties of Reactively Sputtered Gallium Nitride Films. Thin Solid Films 1981, 83, L137-L140.

(3) Porowski, S. Growth and Properties of Single Crystalline GaN Substrates and Homoepitaxial Layers. Mater. Sci. Eng., B 1997, 44, 407-413.

(4) Ilegems, M.; Montgomery, H. C. Electrical Properties of $n$-Type Vapor-Grown Gallium Nitride. J. Phys. Chem. Solids 1973, 34, 885895.

(5) Asif Khan, M.; Bhattarai, A.; Kuznia, J. N.; Olson, D. T. High Electron Mobility Transistor Based on a $\mathrm{GaN}_{-} \mathrm{Al}_{\mathrm{x}} \mathrm{Ga}_{1-}{ }_{\mathrm{x}} \mathrm{N}$ Heterojunction. Appl. Phys. Lett. 1993, 63, 1214-1215.

(6) Strite, S.; Morkoç, H. GaN, AlN, and InN: A Review. J. Vac. Sci. Technol., B: Microelectron. Nanometer Struct.-Process., Meas., Phenom. 1992, 10, 1237-1266.

(7) Amano, H.; Baines, Y.; Beam, E.; Borga, M.; Bouchet, T.; Chalker, P. R.; Charles, M.; Chen, K. J.; Chowdhury, N.; Chu, R.; et al. The $2018 \mathrm{GaN}$ Power Electronics Roadmap. J. Phys. D: Appl. Phys. 2018, 51, 163001.

(8) Li, G.; Wang, W.; Yang, W.; Lin, Y.; Wang, H.; Lin, Z.; Zhou, S. GaN-Based Light-Emitting Diodes on Various Substrates: A Critical Review. Rep. Prog. Phys. 2016, 79, No. 056501.

(9) Bardsley, N.; Bland, S.; Chwastyk, D.; Monasterio, C.; Pattison, L.; Pattison, M.; Welsh, F.; Yamada, M. Manufacturing Roadmap SolidState Lighting Research and Development; U.S. Department of Energy: Washington, DC 2014.

(10) Zhang, Y.; Piedra, D.; Sun, M.; Hennig, J.; Dadgar, A.; Yu, L.; Palacios, T. High-Performance 500 V Quasi- and Fully-Vertical GaNon-Si pn Diodes. IEEE Electron Device Lett. 2017, 38, 248-251.

(11) Zhu, D.; Wallis, D. J.; Humphreys, C. J. Prospects of III-Nitride Optoelectronics Grown on Si. Rep. Prog. Phys. 2013, 76, 106501.

(12) Ishikawa, H.; Yamamoto, K.; Egawa, T.; Soga, T.; Jimbo, T.; Umeno, M. Thermal Stability of GaN on ( $\left.\begin{array}{lll}1 & 1 & 1\end{array}\right)$ Si Substrate. J. Cryst. Growth 1998, 189-190, 178-182.

(13) Ishikawa, H.; Zhao, G.-Y.; Nakada, N.; Egawa, T.; Jimbo, T.; Umeno, M. GaN on Si Substrate with AlGaN/AlN Intermediate Layer. Jpn. J. Appl. Phys. 1999, 38, L492.

(14) Amano, H.; Sawaki, N.; Akasaki, I.; Toyoda, Y. Metalorganic Vapor Phase Epitaxial Growth of a High Quality GaN Film Using an AlN Buffer Layer. Appl. Phys. Lett. 1986, 48, 353-355.

(15) Ikeda, N.; Niiyama, Y.; Kambayashi, H.; Sato, Y.; Nomura, T.; Kato, S.; Yoshida, S. GaN Power Transistors on Si Substrates for Switching Applications. Proc. IEEE 2010, 98, 1151-1161.

(16) Able, A.; Wegscheider, W.; Engl, K.; Zweck, J. Growth of Crack-Free GaN on $\mathrm{Si}\left(\begin{array}{lll}1 & 1 & 1\end{array}\right)$ with Graded AlGaN Buffer Layers. J. Cryst. Growth 2005, 276, 415-418.

(17) Siegmund, O.; Vallerga, J.; McPhate, J.; Malloy, J.; Tremsin, A.; Martin, A.; Ulmer, M.; Wessels, B. Development of GaN Photocathodes for UV Detectors. Nucl. Instrum. Methods Phys. Res., Sect. A 2006, 567, 89-92.
(18) Lee, Y. S.; Kim, D.-S.; Won, C.-H.; Kim, J.-H.; Bu, C.-H.; Hahm, S.-H.; Jung, Y.-C.; Lee, J.-H. Formation of GaN Film on Si for Microbolometer. Proc. SPIE 2012, 835318.

(19) Yagi, S. Highly Sensitive Ultraviolet Photodetectors Based on Mg-Doped Hydrogenated GaN Films Grown at $380{ }^{\circ} \mathrm{C}$. Appl. Phys. Lett. 2000, 76, 345-347.

(20) Bolat, S.; Tekcan, B.; Ozgit-Akgun, C.; Biyikli, N.; Okyay, A. K. Electronic and Optical Device Applications of Hollow Cathode Plasma Assisted Atomic Layer Deposition Based GaN Thin Films. J. Vac. Sci. Technol., A 2015, 33, No. 01A143.

(21) Bour, D. P.; Nickel, N. M.; Van de Walle, C. G.; Kneissl, M. S.; Krusor, B. S.; Mei, P.; Johnson, N. M. Polycrystalline Nitride Semiconductor Light-Emitting Diodes Fabricated on Quartz Substrates. Appl. Phys. Lett. 2000, 76, 2182-2184.

(22) Asahi, H.; Iwata, K.; Tampo, H.; Kuroiwa, R.; Hiroki, M.; Asami, K.; Nakamura, S.; Gonda, S. Very Strong Photoluminescence Emission from GaN Grown on Amorphous Silica Substrate by Gas Source MBE. J. Cryst. Growth 1999, 201-202, 371-375.

(23) Choi, J. H.; Zoulkarneev, A.; Kim, S. I.; Baik, C. W.; Yang, M. H.; Park, S. S.; Suh, H.; Kim, U. J.; Son, H. B.; Lee, J. S.; et al. Nearly Single-Crystalline GaN Light-Emitting Diodes on Amorphous Glass Substrates. Nat. Photonics 2011, 5, 763.

(24) Choi, J. H.; Ahn, H. Y.; Lee, Y. S.; Park, K.; Kim, T.-H.; Cho, K. S.; Baik, C. W.; Kim, S. I.; Yoo, H.; Lee, E. H.; et al. GaN LightEmitting Diodes on Glass Substrates with Enhanced Electroluminescence. J. Mater. Chem. 2012, 22, 22942-22948.

(25) Bolat, S.; Ozgit-Akgun, C.; Tekcan, B.; Biyikli, N.; Okyay, A. K. Low Temperature Thin Film Transistors with Hollow Cathode Plasma-Assisted Atomic Layer Deposition Based GaN Channels. Appl. Phys. Lett. 2014, 104, 243505.

(26) Bolat, S.; Sisman, Z.; Okyay, A. K. Demonstration of Flexible Thin Film Transistors with GaN Channels. Appl. Phys. Lett. 2016, 109, 233504.

(27) Street, R. A., Ed.; Technology and Applications of Amorphous Silicon; Springer Science \& Business Media, 2013; Vol. 37.

(28) Biju, K. P.; Subrahmanyam, A.; Jain, M. K. Low-Temperature Growth of Polycrystalline GaN Films Using Modified Activated Reactive Evaporation. J. Cryst. Growth 2009, 311, 2275-2280.

(29) Chen, R.; Zhou, W.; Sing Kwok, H. Top-Gate Thin-Film Transistors Based on GaN Channel Layer. Appl. Phys. Lett. 2012, 100, No. 022111.

(30) Gupta, G.; Banerjee, S.; Dutta, S.; Aarnink, A. A. I.; Schmitz, J.; Kovalgin, A. Y.; Hueting, R. J. E. Charge Carrier Transport and Electroluminescence in Atomic Layer Deposited Poly-GaN/c-Si Heterojunction Diodes. J. Appl. Phys. 2018, 124, No. 084503.

(31) Johnson, R. W.; Hultqvist, A.; Bent, S. F. A Brief Review of Atomic Layer Deposition: From Fundamentals to Applications. Mater. Today 2014, 17, 236-246.

(32) George, S. M. Atomic Layer Deposition: An Overview. Chem. Rev. 2010, 110, 111-131.

(33) Kim, H.; Lee, H.-B.-R.; Maeng, W.-J. Applications of Atomic Layer Deposition to Nanofabrication and Emerging Nanodevices. Thin Solid Films 2009, 517, 2563-2580.

(34) Kim, H. Atomic Layer Deposition of Metal and Nitride Thin Films: Current Research Efforts and Applications for Semiconductor Device Processing. J. Vac. Sci. Technol., B: Microelectron. Nanometer Struct.-Process., Meas., Phenom. 2003, 21, 2231-2261.

(35) Biyikli, N.; Haider, A. Atomic Layer Deposition: An Enabling Technology for the Growth of Functional Nanoscale Semiconductors. Semicond. Sci. Technol. 2017, 32, No. 093002.

(36) Alevli, M.; Gungor, N. Influence of $\mathrm{N}_{2} / \mathrm{H}_{2}$ and $\mathrm{N}_{2}$ Plasma on Binary III-Nitride Films Prepared by Hollow-Cathode PlasmaAssisted Atomic Layer Deposition. J. Vac. Sci. Technol., A 2018, 36, No. 01A110.

(37) Alevli, M.; Haider, A.; Kizir, S.; Leghari, S. A.; Biyikli, N. Comparison of Trimethylgallium and Triethylgallium as "Ga" Source Materials for the Growth of Ultrathin GaN Films on Si (100) Substrates Via Hollow-Cathode Plasma-Assisted Atomic Layer Deposition. J. Vac. Sci. Technol., A 2016, 34, No. 01A137. 
(38) Ozgit, C.; Donmez, I.; Alevli, M.; Biyikli, N. Atomic Layer Deposition of GaN at Low Temperatures. J. Vac. Sci. Technol., A 2012, 30, No. 01A124.

(39) Ozgit-Akgun, C.; Goldenberg, E.; Okyay, A. K.; Biyikli, N. Hollow Cathode Plasma-Assisted Atomic Layer Deposition of Crystalline AlN, GaN and $\mathrm{Al}_{\mathrm{x}} \mathrm{Ga}_{1-} \mathrm{N}$ Thin Films at Low Temperatures. J. Mater. Chem. C 2014, 2, 2123-2136.

(40) Ozgit-Akgun, C.; Kayaci, F.; Vempati, S.; Haider, A.; Celebioglu, A.; Goldenberg, E.; Kizir, S.; Uyar, T.; Biyikli, N. Fabrication of Flexible Polymer-GaN Core-Shell Nanofibers by the Combination of Electrospinning and Hollow Cathode PlasmaAssisted Atomic Layer Deposition. J. Mater. Chem. C 2015, 3, 5199-5206.

(41) Haider, A.; Deminskyi, P.; Yilmaz, M.; Elmabruk, K.; Yilmaz, I.; Biyikli, N. Long-Range Ordered Vertical III-Nitride Nano-Cylinder Arrays Via Plasma-Assisted Atomic Layer Deposition. J. Mater. Chem. C 2018, 6, 6471-6482.

(42) Kizir, S.; Haider, A.; Biyikli, N. Substrate Impact on the LowTemperature Growth of GaN Thin Films by Plasma-Assisted Atomic Layer Deposition. J. Vac. Sci. Technol., A 2016, 34, No. 041511.

(43) Motamedi, P.; Dalili, N.; Cadien, K. A Route to Low Temperature Growth of Single Crystal GaN on Sapphire. J. Mater. Chem. C 2015, 3, 7428-7436.

(44) Motamedi, P.; Cadien, K. Structure-Property Relationship and Interfacial Phenomena in GaN Grown on C-Plane Sapphire Via Plasma-Enhanced Atomic Layer Deposition. RSC Adv. 2015, 5, 57865-57874.

(45) Pansila, P.; Kanomata, K.; Miura, M.; Ahmmad, B.; Kubota, S.; Hirose, F. Growth Kinetics for Temperature-Controlled Atomic Layer Deposition of GaN Using Trimethylgallium and Remote-PlasmaExcited $\mathrm{NH}_{3}$. Appl. Surf. Sci. 2015, 357, 1920-1927.

(46) Shih, H.-Y.; Lin, M.-C.; Chen, L.-Y.; Chen, M.-J. Uniform GaN Thin Films Grown on (100) Silicon by Remote Plasma Atomic Layer Deposition. Nanotechnology 2014, 26, No. 014002.

(47) Sprenger, J. K.; Cavanagh, A. S.; Sun, H.; Wahl, K. J.; Roshko, A.; George, S. M. Electron Enhanced Growth of Crystalline Gallium Nitride Thin Films at Room Temperature and $100{ }^{\circ} \mathrm{C}$ Using Sequential Surface Reactions. Chem. Mater. 2016, 28, 5282-5294.

(48) Sumakeris, J.; Sitar, Z.; Ailey-Trent, K. S.; More, K. L.; Davis, R. F. Layer-by-Layer Epitaxial Growth of $\mathrm{GaN}$ at Low Temperatures. Thin Solid Films 1993, 225, 244-249.

(49) Kim, O. H.; Kim, D.; Anderson, T. Atomic Layer Deposition of GaN Using $\mathrm{GaCl}_{3}$ and $\mathrm{NH}_{3}$. J. Vac. Sci. Technol., A 2009, 27, 923928.

(50) Tsuchiya, H.; Akamatsu, M.; Ishida, M.; Hasegawa, F. Layer-byLayer Growth of GaN on GaAs Substrates by Alternate Supply of $\mathrm{GaCl}_{3}$ and $\mathrm{NH}_{3}$. Jpn. J. Appl. Phys. 1996, 35, L748.

(51) Koukitu, A.; Kumagai, Y.; Taki, T.; Seki, H. Halogen-Transport Atomic-Layer Epitaxy of Cubic GaN Monitored by In Situ Gravimetric Method. Jpn. J. Appl. Phys. 1999, 38, 4980.

(52) Banerjee, S.; Kovalgin, A. Y. A Comparative Study of LowTemperature III-V Nitrides ALD in Thermal and Radical-Enhanced Modes. ECS Trans. 2018, 86, 21-29.

(53) Banerjee, S.; Onnink, A. J.; Dutta, S.; Aarnink, A. A. I.; Gravesteijn, D. J.; Kovalgin, A. Y. Composite GaN - C - Ga ('GaCN') Layers with Tunable Refractive Index. J. Phys. Chem. C 2018, 122, 29567-29576.

(54) Profijt, H. B.; Potts, S. E.; van de Sanden, M. C. M.; Kessels, W. M. M. Plasma-Assisted Atomic Layer Deposition: Basics, Opportunities, and Challenges. J. Vac. Sci. Technol., A 2011, 29, No. 050801.

(55) Kovalgin, A. Y.; Yang, M.; Banerjee, S.; Apaydin, R. O.; Aarnink, A. A. I.; Kinge, S.; Wolters, R. A. M. Hot-Wire Assisted ALD: A Study Powered by In Situ Spectroscopic Ellipsometry. Adv. Mater. Interfaces 2017, 4, 1700058.

(56) Bartram, M. E.; Michalske, T. A.; Rogers, J. W., Jr.; Paine, R. T. Nucleation and Growth of Aluminum Nitride: Self-Limiting Reactions and the Regeneration of Active Sites Using Sequential Exposures of Trimethylaluminum and Ammonia on Silica at $600 \mathrm{~K}$. Chem. Mater. 1993, 5, 1424-1430.
(57) Creighton, J. R.; Wang, G. T. Reversible Adduct Formation of Trimethylgallium and Trimethylindium with Ammonia. J. Phys. Chem. A 2005, 109, 133-137.

(58) Wang, H. Y.; Huang, S. C.; Yan, T. Y.; Gong, J. R.; Lin, T. Y.; Chen, Y. F. Growth and Characterization of GaN Films on (0001) Sapphire Substrates by Alternate Supply of Trimethylgallium and $\mathrm{NH}_{3}$. Mater. Sci. Eng., B 1999, 57, 218-223.

(59) Karam, N. H.; Parodos, T.; Colter, P.; McNulty, D.; Rowland, W.; Schetzina, J.; El-Masry, N.; Bedair, S. M. Growth of Device Quality $\mathrm{GaN}$ at $550{ }^{\circ} \mathrm{C}$ by Atomic Layer Epitaxy. Appl. Phys. Lett. 1995, 67, 94-96.

(60) Tompkins, H. G.; Irene, E. A., Eds.; Handbook of Ellipsometry; William Andrew, 2005.

(61) Bartram, M. E.; Michalske, T. A.; Rogers, J. W., Jr.; Mayer, T. M. Chemisorption of Trimethylaluminum and Ammonia on Silica: Mechanisms for the Formation of Aluminum-Nitrogen Bonds and the Elimination of Methyl Groups Bonded to Aluminum. Chem. Mater. 1991, 3, 953-960.

(62) Mayer, T. M.; Rogers, J. W., Jr.; Michalske, T. A. Mechanism of Nucleation and Atomic Layer Growth of Aluminum Nitride on Silicon. Chem. Mater. 1991, 3, 641-646.

(63) Puurunen, R. L.; Root, A.; Sarv, P.; Viitanen, M. M.; Brongersma, H. H.; Lindblad, M.; Krause, A. O. I. Growth of Aluminum Nitride on Porous Alumina and Silica Through Separate Saturated Gas-Solid Reactions of Trimethylaluminum and Ammonia. Chem. Mater. 2002, 14, 720-729.

(64) Puurunen, R. L.; Root, A.; Sarv, P.; Haukka, S.; Iiskola, E. I.; Lindblad, M.; Krause, A. O. I. Growth of Aluminium Nitride on Porous Silica by Atomic Layer Chemical Vapour Deposition. Appl. Surf. Sci. 2000, 165, 193-202.

(65) Puurunen, R. L.; Lindblad, M.; Root, A.; Krause, A. O. I. Successive Reactions of Gaseous Trimethylaluminium and Ammonia on Porous Alumina. Phys. Chem. Chem. Phys. 2001, 3, 1093-1102.

(66) Yu, Z. J.; Edgar, J. H.; Ahmed, A. U.; Rys, A. Metalorganic Surface Chemical Adsorption Deposition of AlN Films by Ammonia and Trimethylaluminum. J. Electrochem. Soc. 1991, 138, 196-199.

(67) Bartram, M. E.; Michalske, T. A.; Rogers, J. W., Jr. A Reexamination of the Chemisorption of Trimethylaluminum on Silica. J. Phys. Chem. 1991, 95, 4453-4463.

(68) Sauls, F. C.; Interrante, L. V. Coordination Compounds of Aluminum as Precursors to Aluminum Nitride. Coord. Chem. Rev. 1993, 128, 193-207.

(69) Sauls, F. C.; Interrante, L. V.; Jiang, Z. Ammine (Trimethyl) Aluminum Formation and Pyrolytic Methane Loss: Thermodynamics, Kinetics, and Mechanism. Inorg. Chem. 1990, 29, 2989-2996.

(70) Bronikowski, M. J.; Hamers, R. J. The Chemistry of Gallium Deposition on $\mathrm{Si}(001)$ from Trimethylgallium: An Atomically Resolved STM Study. Surf. Sci. 1996, 348, 311-324.

(71) Lee, F.; Backman, A. L.; Lin, R.; Gow, T. R.; Masel, R. I. Decomposition of Trimethylgallium on $\mathrm{Si}(100)$ : Spectroscopic Identification of the Intermediates. Surf. Sci. 1989, 216, 173-188.

(72) Sengupta, D.; Mazumder, S.; Kuykendall, W.; Lowry, S. A. Combined ab initio Quantum Chemistry and Computational Fluid Dynamics Calculations for Prediction of Gallium Nitride Growth. J. Cryst. Growth 2005, 279, 369-382.

(73) Mazzarese, D.; Tripathi, A.; Conner, W. C.; Jones, K. A.; Calderon, L.; Eckart, D. W. In situ FTIR and Surface Analysis of the Reaction of Trimethylgallium and Ammonia. J. Electron. Mater. 1989, 18, 369-377.

(74) Kuech, T. F., Ed. In Handbook of Crystal Growth: Thin Films and Epitaxy: Basic Techniques, and Materials, Processes, and Technology; 2nd Ed.; Elsevier: 2015; Vol. IIIA, pp 869-907.

(75) Mihopoulos, T. Reaction and Transport Processes in OMCVD: Selective and Group III-Nitride Growth. Ph.D. Dissertation, Massachusetts Institute of Technology, Cambridge, MA, 1999.

(76) Parikh, R. P.; Adomaitis, R. A. An Overview of Gallium Nitride Growth Chemistry and Its Effect on Reactor Design: Application to a Planetary Radial-Flow CVD System. J. Cryst. Growth 2006, 286, 259278. 
(77) An, Q.; Jaramillo-Botero, A.; Liu, W.-G.; Goddard, W. A., III Reaction Pathways of GaN (0001) Growth from Trimethylgallium and Ammonia Versus Triethylgallium and Hydrazine Using First Principle Calculations. J. Phys. Chem. C 2015, 119, 4095-4103.

(78) Wang, K.; Singh, J.; Pavlidis, D. Theoretical Study of GaN Growth: A Monte Carlo Approach. J. Appl. Phys. 1994, 76, 35023510.

(79) Almond, M. J.; Jenkins, C. E.; Rice, D. A.; Hagen, K. Organometallic Precursors to the Formation of GaN by MOCVD: Structural Characterisation of $\mathrm{Me}_{3} \mathrm{Ga} \cdot \mathrm{NH}_{3}$ by Gas-Phase Electron Diffraction. J. Organomet. Chem. 1992, 439, 251-261.

(80) Thon, A.; Kuech, T. F. High Temperature Adduct Formation of Trimethylgallium and Ammonia. Appl. Phys. Lett. 1996, 69, 55-57.

(81) Creighton, J. R.; Wang, G. T. Kinetics of Metal OrganicAmmonia Adduct Decomposition: Implications for Group-III Nitride MOCVD. J. Phys. Chem. A 2005, 109, 10554-10562.

(82) Wang, G. T.; Creighton, J. R. Complex Formation of Trimethylaluminum and Trimethylgallium with Ammonia: Evidence for a Hydrogen-Bonded Adduct. J. Phys. Chem. A 2006, 110, 10941099.

(83) Moscatelli, D.; Cavallotti, C. Theoretical Investigation of the Gas-Phase Kinetics Active During the GaN MOVPE. J. Phys. Chem. A 2007, 111, 4620-4631.

(84) Creighton, J. R.; Wang, G. T.; Breiland, W. G.; Coltrin, M. E. Nature of the Parasitic Chemistry During AlGaInN OMVPE. J. Cryst. Growth 2004, 261, 204-213.

(85) Creighton, J. R.; Wang, G. T.; Coltrin, M. E. Fundamental Chemistry and Modeling of Group-III Nitride MOVPE. J. Cryst. Growth 2007, 298, 2-7.

(86) Safvi, S. A.; Redwing, J. M.; Tischler, M. A.; Kuech, T. F. GaN Growth by Metallorganic Vapor Phase Epitaxy A Comparison of Modeling and Experimental Measurements. J. Electrochem. Soc. 1997, 144, 1789-1796.

(87) Schäfer, J.; Simons, A.; Wolfrum, J.; Fischer, R. A. Detection of Gas-Phase Species in MOCVD of GaN Using Molecular Beam Quadrupole Mass Spectrometry. Chem. Phys. Lett. 2000, 319, 477481.

(88) Demchuk, A.; Porter, J.; Koplitz, B. Laser-Assisted Reactivity of Triethylgallium or Trimethylgallium with Ammonia in Constrained Pulsed Nozzle Expansions. J. Phys. Chem. A 1998, 102, 8841-8846.

(89) Bergmann, U.; Reimer, V.; Atakan, B. An Experimental Study of the Reactions of Trimethylgallium with Ammonia and Water over a Wide Temperature Range. Phys. Chem. Chem. Phys. 1999, 1, 55935599.

(90) Sywe, B. S.; Schlup, J. R.; Edgar, J. H. Fourier Transform Infrared Spectroscopic Study of Predeposition Reactions in Metalloorganic Chemical Vapor Deposition of Gallium Nitride. Chem. Mater. 1991, 3, 737-742.

(91) Coltrin, M. E.; Creighton, J. R.; Mitchell, C. C. Modeling the Parasitic Chemical Reactions of AlGaN Organometallic Vapor-Phase Epitaxy. J. Cryst. Growth 2006, 287, 566-571.

(92) Mondal, B.; Mandal, D.; Ghosh, D.; Das, A. K. Computational Study on the Growth of Gallium Nitride and a Possible Source of Oxygen Impurity. J. Phys. Chem. A 2010, 114, 5016-5025.

(93) Timoshkin, A. Y.; Schaefer, H. F., III From Charge Transfer Complexes to Nanorods. J. Phys. Chem. C 2008, 112, 13816-13836.

(94) Sengupta, D. Does the Ring Compound $\left[\left(\mathrm{CH}_{3}\right)_{2} \mathrm{GaNH}_{2}\right]_{3}$ Form During MOVPE of Gallium Nitride? Investigations via Density Functional and Reaction Rate Theories. J. Phys. Chem. B 2003, 107, 291-297.

(95) Ravasio, S.; Momose, T.; Fujii, K.; Shimogaki, Y.; Sugiyama, M.; Cavallotti, C. Analysis of the Gas Phase Kinetics Active During GaN Deposition from $\mathrm{NH}_{3}$ and $\mathrm{Ga}\left(\mathrm{CH}_{3}\right)_{3}$. J. Phys. Chem. A 2015, 119, 7858-7871.

(96) Pelekh, A.; Carr, R. W. Gas-Phase Reaction of Trimethylgallium and Ammonia: Experimental Determination of the Equilibrium Constant and ab Initio Calculations. J. Phys. Chem. A 2001, 105, $4697-4701$.
(97) Tachibana, A.; Makino, O.; Tanimura, S.; Tokunaga, H.; Akutsu, N.; Matsumoto, K. Quantum Chemical Studies of Gas Phase Reactions between TMA, TMG, TMI and $\mathrm{NH}_{3}$. Phys. Status Solidi $A$ 1999, 176, 699-703.

(98) Allred, A. L. Electronegativity Values from Thermochemical Data. J. Inorg. Nucl. Chem. 1961, 17, 215-221.

(99) Masel, R. I. Principles of Adsorption and Reaction on Solid Surfaces; John Wiley \& Sons, 1996; Vol. 3.

(100) Theodoropoulos, C.; Mountziaris, T. J.; Moffat, H. K.; Han, J. Design of Gas Inlets for the Growth of Gallium Nitride by Metalorganic Vapor Phase Epitaxy. J. Cryst. Growth 2000, 217, 6581.

(101) de Castro, A.; Alegre, D.; Tabarés, F. L. Physisorption of Ammonia on AISI 304 L Stainless Steel at Different Surface Temperature under High Vacuum Conditions. Nucl. Mater. Energy 2016, 9, 1-5.

(102) Onnink, A. J.; Apaydin, R. O.; Schmitz, J.; Kovalgin, A. Y. InSitu Study of Ammonium Bromide Formation for Optimizing Boron Nitride ALD from $\mathrm{BBr}_{3}$ and $\mathrm{NH}_{3}$. EuroCVD 22 - Baltic ALD 16 Conference; Luxembourg Institute of Science and Technology: Luxembourg City, Luxembourg, June 24-28, 2019.

(103) Miyazaki, T.; Takada, K.; Adachi, S.; Ohtsuka, K. Properties of Radio-Frequency-Sputter-Deposited GaN Films in a Nitrogen/ Hydrogen Mixed Gas. J. Appl. Phys. 2005, 97, No. 093516.

(104) Socrates, G. Infrared and Raman Characteristic Group Frequencies: Tables and Charts; John Wiley \& Sons, 2001.

(105) Barr, T. L.; Seal, S. Nature of the Use of Adventitious Carbon as a Binding Energy Standard. J. Vac. Sci. Technol., A 1995, 13, 12391246.

(106) Lee, S. S.; Park, S. M.; Chong, P. J. Single-Phase Deposition of $\alpha$-Gallium Nitride by a Laser-Induced Transport Process. J. Mater. Chem. 1993, 3, 347-351.

(107) Carin, R.; Deville, J. P.; Werckmann, J. An XPS Study of GaN Thin Films on GaAs. Surf. Interface Anal. 1990, 16, 65-69.

(108) Jia, Y.; Wallace, J. S.; Echeverria, E.; Gardella, J. A., Jr.; Singisetti, U. Interface Characterization of Atomic Layer Deposited $\mathrm{Al}_{2} \mathrm{O}_{3}$ on m-Plane GaN. Phys. Status Solidi B 2017, 254, 1600681.

(109) Watkins, N. J.; Wicks, G. W.; Gao, Y. Oxidation Study of GaN Using X-Ray Photoemission Spectroscopy. Appl. Phys. Lett. 1999, 75, 2602-2604

(110) Wolter, S. D.; Luther, B. P.; Waltemyer, D. L.; Önneby, C.; Mohney, S. E.; Molnar, R. J. X-ray Photoelectron Spectroscopy and Xray Diffraction Study of the Thermal Oxide on Gallium Nitride. Appl. Phys. Lett. 1997, 70, 2156-2158.

(111) Bourque, J. L.; Biesinger, M. C.; Baines, K. M. Chemical State Determination of Molecular Gallium Compounds Using XPS. Dalton Trans. 2016, 45, 7678-7696.

(112) Kong, M.-Y.; Zhang, J.-P.; Wang, X.-L.; Sun, D.-Z. Hydrogen Behavior in $\mathrm{GaN}$ Epilayers Grown by $\mathrm{NH}_{3}$-MBE. J. Cryst. Growth 2001, 227-228, 371-375. 